\title{
Future changes in European winter storm losses and extreme wind speeds inferred from GCM and RCM multi-model simulations
}

\author{
M. G. Donat ${ }^{1,2}$, G. C. Leckebusch ${ }^{1}$, S. Wild ${ }^{1}$, and U. Ulbrich ${ }^{1}$ \\ ${ }^{1}$ Institute of Meteorology, Freie Universität Berlin, Germany \\ ${ }^{2}$ Climate Change Research Centre, University of New South Wales, Sydney, Australia
}

Received: 12 December 2009 - Revised: 18 February 2011 - Accepted: 24 March 2011 - Published: 12 May 2011

\begin{abstract}
Extreme wind speeds and related storm loss potential in Europe have been investigated using multi-model simulations from global (GCM) and regional (RCM) climate models. Potential future changes due to anthropogenic climate change have been analysed from these simulations following the IPCC SRES A1B scenario. The large number of available simulations allows an estimation of the robustness of detected future changes. All the climate models reproduced the observed spatial patterns of wind speeds, although some models displayed systematic biases. A storm loss model was applied to the GCM and RCM simulated wind speeds, resulting in realistic mean loss amounts calculated from 20th century climate simulations, although the inter-annual variability of losses is generally underestimated. In future climate simulations, enhanced extreme wind speeds were found over northern parts of Central and Western Europe in most simulations and in the ensemble mean (up to 5\%). As a consequence, the loss potential is also higher in these regions, particularly in Central Europe. Conversely, a decrease in extreme wind speeds was found in Southern Europe, as was an associated reduction in loss potential. There was considerable spread in the projected changes of individual ensemble members, with some indicating an opposite signature to the ensemble mean. Downscaling of the large-scale simulations with RCMs has been shown to be an important source of uncertainty. Even RCMs with identical boundary forcings can show a wide range of potential changes. The robustness of the projected changes was estimated using two different measures. First, the inter-model standard deviation was calculated; however, it is sensitive to outliers and thus displayed large uncertainty ranges. Second, a multimodel combinatorics approach considered all possible subensembles from GCMs and RCMs, hence taking into account
\end{abstract}

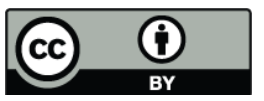

Correspondence to: M. G. Donat (m.donat@unsw.edu.au) the arbitrariness of model selection for multi-model studies. Based on all available GCM and RCM simulations, for example, a 25\% mean increase in risk of loss for Germany has been estimated for the end of the 21 st century, with a $90 \%$ confidence range of +15 to $+35 \%$.

\section{Introduction}

Mid-latitude winter storms frequently hit Europe, causing high wind speeds over large areas and thus leading to the risk of high losses. Apart from the danger of injury or even loss of lives, such events cause heavy damage, particularly to infrastructure. In Germany, for example, 53\% of economic losses due to natural hazards and $64 \%$ of insured losses are caused by winter storms (Munich Re, 1999, 2007). The related losses often amount to several hundred millions of Euros for single events; thus, wind storms are the most loss-intensive natural hazards in Central Europe. The various institutions involved in planning, rescue and insurance thus need to obtain information about the potential effects of anthropogenic climate change (ACC) on the risk of such extreme events.

A number of recent studies have investigated changes in storminess in ACC scenario simulations using global climate models (GCMs) and found indications of more frequent intensive cyclones over the eastern North Atlantic (Bengtsson et al., 2006; Lambert and Fyfe, 2006; Leckebusch et al., 2006) and an eastward extension of the North Atlantic storm track (Ulbrich et al., 2008). These results are in line with the findings of higher extreme wind speeds over parts of Western and Central Europe (Knippertz et al., 2000; Leckebusch and Ulbrich, 2004; Pinto et al., 2007; Gastineau and Soden, 2009). On the basis of multi-model GCM simulations, Donat et al. (2010a) found increased frequencies of storm days under future climate conditions and increased wind speeds during storm events. Studies estimating changes in storm losses under ACC conditions found increased risk of losses,

Published by Copernicus Publications on behalf of the European Geosciences Union. 
particularly in Western and Central Europe, if buildings had not been adapted to higher wind speeds (Leckebusch et al., 2007; Pinto et al., 2007).

Such GCM-based investigations may be supplemented by applying dynamical downscaling using regional climate models (RCMs). Simulated atmospheric parameters are thus obtained at a higher spatial resolution, in particular providing information on the influence of regional orographic characteristics. Additionally, physical processes acting at scales resolved by the RCMs (but not by the GCMs) might affect the simulated regional wind patterns. The advantage of dynamical downscaling with respect to wind fields over complex terrain was demonstrated by, for example, Goyette et al. (2003), Žagar et al. (2006), Hofherr and Kunz (2010) and Kunz et al. (2010), who obtained more realistic wind speeds compared to the driving large-scale data, in particular over mountainous regions. An improved representation of local wind speeds should enhance the accuracy of storm loss calculations. The benefit of dynamical downscaling for storm loss calculations was investigated in a recent study using loss data for Germany (Donat et al., 2010b). Future changes of extreme wind speeds in multi-model RCM simulations (all driven by the same GCM) were explored by Rockel and Woth (2007), who found increased speed values in Central and Western Europe during winter. ACC signals of wind speed patterns in RCM simulations driven by different GCMs had previously been compared to the large-scale GCM signals, e.g., by Leckebusch et al. (2006).

Numerical climate model simulations are affected by various uncertainties, the most important ones being model uncertainties, uncertainty due to internal variability, and sensitivity to the initial conditions and to boundary conditions (Murphy et al., 2004; Stainforth et al., 2005; Giorgi, 2006). Wind storm occurrence has particularly high variability (Bärring and von Storch, 2004; Wang et al., 2009). Hence, a reliable estimation of long-term changes requires large samples, which can also be obtained from ensemble simulations (see, for example, Della-Marta et al., 2010; Donat et al., 2010a).

Combining different models into a multi-model ensemble (MME) generally increases the skill, reliability and consistency of model projections. The value of MMEs for weather and seasonal prediction applications has been widely shown (e.g., by Hagedorn et al., 2005), and verification and quantification are relatively straightforward using skill measures, for example. For climate-timescale simulations, an MME can also be useful for estimating the robustness of the detected changes (Palmer and Räisänen, 2002; Räisänen, 2007; Collins, 2007). MMEs primarily sample model uncertainties and the uncertainty due to internal variability. Hence, MMEs of climate simulations permit the pure GHG forcing effect to be analysed separately from the internal variability, as the different phases of variability in the individual ensemble members are sampled and may cancel out. On the basis of reanalysis-driven RCM simulations (thus sam- pling only model uncertainties but not internal variability), Donat et al. (2010b) demonstrated the advantage of MMEs for storm loss calculations, showing the ensemble mean performance to be close to the best single model in terms of agreement with observed losses. An increased consistency of results was found for larger ensembles.

This study aims to estimate a range of possible future changes of extreme wind speeds and the related storm loss potential as well as the robustness of these changes based on an MME of GCM and RCM simulations. In addition, the detected climate change signals (i.e., the difference between future and recent climate mean states) for wind and calculated losses in the RCMs are compared to the changes in the driving GCM. The robustness of the future projections is estimated from the differences between the changes in the different ensemble members. We have followed two different approaches to measure the uncertainty related to the projected changes. In addition to considering the inter-model standard deviation, the effect of different ensemble configurations on the loss signals has been examined systematically for all possible combinations of subsets of available models. Probabilistic information about the magnitude of possible changes can thus be derived.

\section{Data and methods}

\subsection{Climate model data}

This study analyses a number of global and regional climate model simulations which were performed in the framework of the ENSEMBLES project (van der Linden and Mitchell, 2009). Nine GCM simulations from five different GCMs were examined (ENSEMBLES project setup, see Table 1a). From each simulation, we analysed a period representing recent greenhouse gas forcing conditions during the last decades of the 20th century (20C, generally the model period 1960-2000 was considered) and a projection of the future climate for the 21st century (21C) according to the SRES A1B scenario (A1B). Two future periods were studied: one for the middle (2021-2050) and one for the end of 21C (2071-2100 of most models). Almost all storm events causing severe damage occurred during the boreal winter (Klawa and Ulbrich, 2003; Munich Re, 2007). Hence, the analyses presented here focus on the extended winter period from October to March.

ERA40 reanalysis (Uppala et al., 2005) was used to validate the GCM and RCM 20C climate period simulations and to calibrate the loss model; the loss regression function thus obtained was also used for loss calculations based on the GCM simulations (see Sect. 2.2).

Our analyses concentrate on the daily maximum 10-m wind speeds from all data sets. This parameter was recorded as the daily maximum speed value, based on all time steps within a $24 \mathrm{~h}$ period. It was derived for almost all GCMs 
Table 1. a Climate models included in this study (ENSEMBLES setup) (a) GCM simulations.

\begin{tabular}{|c|c|c|c|c|c|c|c|}
\hline Model & Institute & $\begin{array}{l}\text { Resolution } \\
\text { atmosphere }\end{array}$ & $20 \mathrm{C}$. & $\begin{array}{c}\text { A1B } \\
(\operatorname{mid} 21 \mathrm{C})\end{array}$ & $\begin{array}{c}\text { A1B } \\
\text { (end 21C) }\end{array}$ & $\begin{array}{c}\text { No. of } \\
\text { considered runs }\end{array}$ & References \\
\hline BCCR-BCM2 & $\begin{array}{l}\text { Bjerkness Centre for } \\
\text { Climate Research }\end{array}$ & T63, L45 & 1960-1999 & $2021-2050$ & 2080-2099 & 1 & Furevik et al. (2003) \\
\hline CNRM-CM3 & $\begin{array}{l}\text { Météo France/Centre } \\
\text { National de Recherches } \\
\text { Météorologiques }\end{array}$ & T63, L31 & $1981-2000$ & $2021-2050$ & $2081-2100$ & 1 & Salas-Mélia et al. (2005) \\
\hline DMI-ECHAM5 & $\begin{array}{l}\text { Danish Meteorological } \\
\text { Institute }\end{array}$ & T63, L31 & $1961-2000$ & $2021-2050$ & $2071-2100$ & 1 & Jungclaus et al. (2006) \\
\hline FUB-EGMAM & $\begin{array}{l}\text { Freie Universität Berlin, } \\
\text { Institute of Meteorology }\end{array}$ & T30, L39 & $1961-2000$ & $2021-2050$ & $2071-2100$ & 1 & $\begin{array}{l}\text { Manzini } \\
\text { and McFarlane (1998) } \\
\text { Legutke and Voss (1999) } \\
\text { Huebener et al. (2007) }\end{array}$ \\
\hline IPSL-CM4 & $\begin{array}{l}\text { Institut Pierre Simon } \\
\text { Laplace }\end{array}$ & $2.5^{\circ} \times 3.75^{\circ}, \mathrm{L} 19$ & $1961-2000$ & $2021-2050$ & $2071-2100$ & 1 & Marti et al. (2005) \\
\hline MPI-ECHAM5 & $\begin{array}{l}\text { Max Planck Institute for } \\
\text { Meteorology }\end{array}$ & T63, L31 & $1961-2000$ & $2021-2050$ & $2071-2100$ & 3 & Jungclaus et al. (2006) \\
\hline METO-HC-HadGEM1 & $\begin{array}{l}\text { UK Met Office, Hadley } \\
\text { Center }\end{array}$ & $1.25^{\circ} \times 1.875^{\circ}, \mathrm{L} 38$ & $1960-1999$ & $2021-2050$ & 2070-2099 & 1 & $\begin{array}{l}\text { Johns et al. (2006) } \\
\text { Martin et al. (2006) } \\
\text { Ringer et al. (2006) }\end{array}$ \\
\hline
\end{tabular}

and for all RCMs. Only 6-hourly instantaneous values of wind speed were available for ERA40 and the GCM simulations with BCCR-BCM2, CNRM-CM3 and DMI-ECHAM5. Hence, a daily maximum was calculated as the maximum of the four instantaneous wind speeds stored at 00:00, 06:00, 12:00 and 18:00 UTC. This value is expected to be slightly smaller than the maximum over all time steps (Pinto et al., 2007, their Fig. 3b, c), introducing a minor inhomogeneity into our data set. The daily maximum wind speed data are hereafter referred to as WIMAX.

All RCM simulations were carried out for a common domain including the whole continental European area (from approximately $10^{\circ} \mathrm{W}$ to $40^{\circ} \mathrm{E}$ and $30^{\circ} \mathrm{N}$ to $65^{\circ} \mathrm{N}$ ). Overall, a set of 14 RCM simulations was considered (see Table $1 \mathrm{~b}$ for a list and description of labelling nomenclature), downscaling seven different GCM runs. Most RCM simulations were carried out at a resolution of $0.22^{\circ}$ (approximately $25 \mathrm{~km}$ ), but two (KNMI-RACMO2_E5_1/2) were performed at a coarser resolution of $0.44^{\circ}$ (approximately $50 \mathrm{~km}$ ). All scenario simulations followed the SRES A1B scenario and were integrated until at least the year 2050. A smaller set of simulations continued until the year 2100 . Thus, we examined potential future changes for the middle (using all models) as well as for the end (using those models integrating until 2100) of the 21st century. For the four HadCM3-driven simulations (C4I-RCA3_HCh, HC-HadRM3_HCn, ETHZCLM_HCn and METNO-HIRHAM_HCn), different realisations from a perturbed parameter GCM ensemble were used for boundary forcing (Collins et al., 2011). Unfortunately, no daily maximum wind speeds were available from these
HadCM3 runs that would allow the RCM signals to be interpreted in context with the large-scale forcing. This was, however, possible for the remaining $10 \mathrm{RCM}$ simulations driven by GCMs also analysed in this study (Sect. 3.1): two each driven by CNRM-CM3 and BCCR-BCM2, four driven by MPI-ECHAM5 run3, one driven by MPI-ECHAM5 run 1, and one by run 2 (Table $1 \mathrm{~b}$ ).

The ensemble of GCM simulations included different realisations of the ECHAM5 model (on which four of the nine simulations are based); hence, the presented results could potentially be biased owing to the dominance of this particular model. As our preference was to include as many simulations as possible in our ensemble, we generally took all nine available simulations into account when computing the GCM ensemble mean. This approach seemed to be reasonable because the changes in the individual realisations with ECHAM5 exhibited a considerable spread (Sect. 3.1), probably due to different phases in the internal variability. Nevertheless, the results obtained by including only one of the ECHAM5 simulations in the ensemble will also be discussed. Similarly, the RCM ensemble consists of different models downscaling the same GCM simulation. As RCMs can reveal considerably different results even with identical large-scale forcing (Sect. 3.2), and given the aim of this study to incorporate as many models as available, all simulations are generally included in the ensemble mean calculations. However, the impacts of alternative ensemble constructions will also be discussed.

Five of the RCMs (used for a total of eight simulations, see Table 1b) also feature a gust parameterisation. The respective 
Table 1. b RCM scenario simulations; the RCM run-labels (as referenced in the text) consist of the abbreviations for the modelling institution, the particular RCM and a code for the driving GCM.

\begin{tabular}{|c|c|c|c|c|c|c|c|c|}
\hline RCM & Institute & Driving GCM & RCM Run-Label & Resolution & $\begin{array}{l}\text { Calculation } \\
\text { of GUST }\end{array}$ & $\begin{array}{l}\text { A1B } \\
(2021- \\
2050)\end{array}$ & $\begin{array}{l}\text { A1B } \\
(2071- \\
2100)\end{array}$ & References \\
\hline C4I-RCA3 & $\begin{array}{l}\text { Community } \\
\text { Climate Change } \\
\text { Consortium for } \\
\text { Ireland }\end{array}$ & $\begin{array}{l}\text { HadCM3-Q16 } \\
\text { (high } \\
\text { sensitivity) }\end{array}$ & C4I-RCA3_HCh & $25 \mathrm{~km}$ & $\mathrm{X}$ & $\mathrm{X}$ & $\mathrm{X}$ & Kjellström et al. (2005) \\
\hline HC-HadRM3 & $\begin{array}{l}\text { UK Met Office, } \\
\text { Hadley Center }\end{array}$ & $\begin{array}{l}\text { HadCM3Q0 } \\
\text { (normal } \\
\text { sensitivity) }\end{array}$ & HC-HadRM3_HCn & $25 \mathrm{~km}$ & & $\mathrm{X}$ & $\mathrm{X}$ & Jones et al. (1995) \\
\hline ETHZ-CLM & $\begin{array}{l}\text { Swiss Federal } \\
\text { Institute of } \\
\text { Technology }\end{array}$ & $\begin{array}{l}\text { HadCM3Q0 } \\
\text { (normal } \\
\text { sensitivity) }\end{array}$ & ETHZ-CLM_HCn & $25 \mathrm{~km}$ & $\mathrm{X}$ & $\mathrm{X}$ & $\mathrm{X}$ & $\begin{array}{l}\text { Steppeler et al. (2003) } \\
\text { Jaeger et al. (2008) }\end{array}$ \\
\hline CNRM-RM4.5 & $\begin{array}{l}\text { Météo } \\
\text { France/Centre } \\
\text { National de } \\
\text { Recherches } \\
\text { Météorologiques }\end{array}$ & CNRM-CM3 & CNRM-RM4.5_C & $25 \mathrm{~km}$ & & $\mathrm{X}$ & & Gibelin and Déqué (2003) \\
\hline DMI-HIRHAM & $\begin{array}{l}\text { Danish } \\
\text { Meteorological } \\
\text { Institute }\end{array}$ & ECHAM5_run3 & DMI-HIRHAM_E5_3 & $25 \mathrm{~km}$ & & $\mathrm{X}$ & $\mathrm{X}$ & Christensen et al. (1996) \\
\hline METNO-HIRHAM & $\begin{array}{l}\text { Norwegian } \\
\text { Meteorological } \\
\text { Institute }\end{array}$ & BCCR-BCM2 & METNO-HIRHAM_B & $25 \mathrm{~km}$ & & $\mathrm{X}$ & & Christensen et al. (1996) \\
\hline METNO-HIRHAM & $\begin{array}{l}\text { Norwegian } \\
\text { Meteorological } \\
\text { Institute }\end{array}$ & $\begin{array}{l}\text { HadCM3Q0 } \\
\text { (normal } \\
\text { sensitivity) }\end{array}$ & METNO-HIRHAM_HCn & $25 \mathrm{~km}$ & & $\mathrm{X}$ & & Christensen et al. (1996) \\
\hline KNMI-RACMO2 & $\begin{array}{l}\text { Royal } \\
\text { Netherlands } \\
\text { Meteorological } \\
\text { Institute }\end{array}$ & ECHAM5_run1 & KNMI-RACMO2_E5_1 & $50 \mathrm{~km}$ & $\mathrm{X}$ & $\mathrm{X}$ & $\mathrm{X}$ & Lenderink et al. (2003) \\
\hline MPI-REMO & $\begin{array}{l}\text { Max Planck } \\
\text { Institute for } \\
\text { Meteorology }\end{array}$ & ECHAM5_run3 & MPI-REMO_E5_3 & $25 \mathrm{~km}$ & $\mathrm{X}$ & $\mathrm{X}$ & $\mathrm{X}$ & $\begin{array}{l}\text { Jacob and Podzun (1997) } \\
\text { Jacob (2001) }\end{array}$ \\
\hline SMHI-RCA3 & $\begin{array}{l}\text { Swedish } \\
\text { Meteorological } \\
\text { and } \\
\text { Hydrological } \\
\text { Institute }\end{array}$ & ECHAM5_run3 & SMHI-RCA3_E5_3 & $25 \mathrm{~km}$ & $\mathrm{X}$ & $\mathrm{X}$ & $\mathrm{X}$ & $\begin{array}{l}\text { Kjellström et al. (2005) } \\
\text { Samuelsson et al. (2011) }\end{array}$ \\
\hline SMHI-RCA3 & $\begin{array}{l}\text { Swedish } \\
\text { Meteorological } \\
\text { and } \\
\text { Hydrological } \\
\text { Institute }\end{array}$ & BCCR-BCM2 & SMHI-RCA3_B & $25 \mathrm{~km}$ & $\mathrm{X}$ & $\mathrm{X}$ & $\mathrm{X}$ & $\begin{array}{l}\text { Kjellström et al. (2005) } \\
\text { Samuelsson et al. (2011) }\end{array}$ \\
\hline
\end{tabular}


daily maximum 10-m gust wind speeds are hereafter referred to as GUST. For the ERA40 dataset, the 10-m wind speed (6-hourly, see above) and a 10-m wind gust are available. As in the RCMs, the latter is an online model diagnostic and hence, based on a parameterisation. Note that different approaches for calculating the gust wind speeds were used in the different models. The method used in the RCA3 models (SMHI and C4I) assumes that surface gusts result from the deflection of air parcels from the upper boundary layer, mixed down by turbulent eddies (Brasseur, 2001). This method takes into account turbulent kinetic energy, the mean wind and the static stability in the boundary layer. ERA40 and KNMI-RACMO2 calculate gust wind speeds by adding a term which comprises the static stability of the boundary layer to the 10-m wind speed (White, 2003). MPI-REMO and ETHZ-CLM calculate gusts based on empirical assumptions, taking into account the turbulent kinetic energy in the lowest model layer (Schrodin, 1995).

\subsection{Calculation of storm-induced losses}

Storm losses have been calculated by applying a linear regression model developed by Klawa and Ulbrich (2003). In recent studies, this model was applied to reanalysis and GCM data (Leckebusch et al., 2007; Pinto et al., 2007) as well as to (reanalysis-driven) RCM simulations (Donat et al., 2010b), yielding reasonable results. Annual loss ratios (giving the ratio of insured values that is affected by storm losses) are calculated by the equation

loss $=A \cdot \sum_{\text {area }}^{\text {country }} \operatorname{pop}($ area $) \cdot \sum_{\text {days }}^{\text {year }} \max \left[0 ;\left(\frac{\mathrm{v}_{\text {max }}(\text { area, day })}{\mathrm{v}_{98}(\text { area })}-1\right)^{3}\right]+B$

In this function, $v_{\max }$ is the daily maximum wind speed (i.e., WIMAX or GUST) in a grid box, and $v_{98}$ is the local 98th percentile of daily maximum wind speeds. Thus, it is assumed that losses occur locally during the $2 \%$ of days with strongest winds. Using a relative threshold, the loss function takes into account model biases of simulated wind speeds. $A$ is the regression coefficient obtained from calibrating calculated losses with the insurance data, $\operatorname{pop}(a r e a)$ is the population density, and $B$ is the axis intercept. Population density is regarded as a proxy for insured values because information about the spatial distribution of total insured values is usually regarded as confidential by insurance companies. The assumption that insured values are proportional to population density is reasonable for developed countries in Central and Western Europe and has been previously shown to be applicable for the calculation of losses (Klawa and Ulbrich, 2003). For the calculations in this study we have used gridded population density data for the year 2000 , on a $0.25 \times 0.25$ degree raster (CIESIN, 2005).

The dimensionless loss index (calculated at each grid point) had to be scaled towards the observed loss data. Therefore, annually accumulated loss data (including losses to residential buildings due to storm and hail events) for Germany were provided by the Gesamtverband der Deutschen Versicherungswirtschaft e.V. (German Insurance Association, hereafter GDV) for the period 1970-2000. Severe losses are usually caused by intense winter storm events affecting a large area; losses due to hail can generally be neglected because their percentage in the total annual loss is small (Klawa and Ulbrich, 2003; GDV, personal communication, 2009). Annual loss values are given as the ratio between insured claims and total insured values (unit: $€$ per $1000 €$, i.e., in $\% o$ ). An advantage of this measure is that inflation can be neglected as it is included both in insured values and in the loss. A linear regression is used to calibrate "raw losses" as calculated by the loss function with the GDV loss ratios. The regression derived for Germany was also used for the other countries considered. Leckebusch et al. (2007) showed that similar results are obtained if damage data from the UK are used to calibrate the calculated loss values. Thus, the calculated loss ratios for other countries than Germany might not be fully realistic in terms of their absolute value, but estimates of future changes will still be possible. In addition to those for Germany, this study also estimates storm losses for Poland, France, Belgium, the Netherlands and Luxembourg (together "BeNeLux"), the United Kingdom and Ireland (together "UK + IRE"), and Spain and Portugal (together "IBERIA"). This selection is motivated by earlier results with respect to future changes of loss potential and cyclone tracks (e.g., Leckebusch et al., 2006, 2007; Donat et al., 2010a). Population densities used for the loss calculations for the regions considered are presented in Fig. 1.

To calculate losses from the GCM simulations, we used the regression coefficients $A$ and $B$ determined for losses calculated from the ERA40 reanalysis. Because the models simulate a specific realisation of climate and generally do not reproduce the observed chronology of events, model years cannot be assigned to observed annual loss data. GCM wind biases compared to ERA40 are less relevant because normalised wind speeds were used rather than absolute model output values. For the RCM simulations, model-specific regressions were determined from simulations driven by ERA40 reanalysis, which are expected to depict the observed chronology of storm events and related losses (Donat et al., 2010b). Again, the percentile approach largely removes deviations of an RCM wind climatology arising from driving the model with GCM data other than ERA40.

Loss potentials for the future climate periods were calculated in two ways: first, the local 98th percentile of daily maximum wind speeds calculated for the $20 \mathrm{C}$ period was maintained as the threshold for the occurrence of losses, also for future climate simulations; second, the percentile of the future simulation was used as the loss threshold. In the first approach, damage was assumed to occur at the same wind speed as it does at present. The second approach took adaptation to a new wind climatology into account. This means that, for example, the architecture of houses is adapted to higher or lower local wind speeds, so that losses again occur 


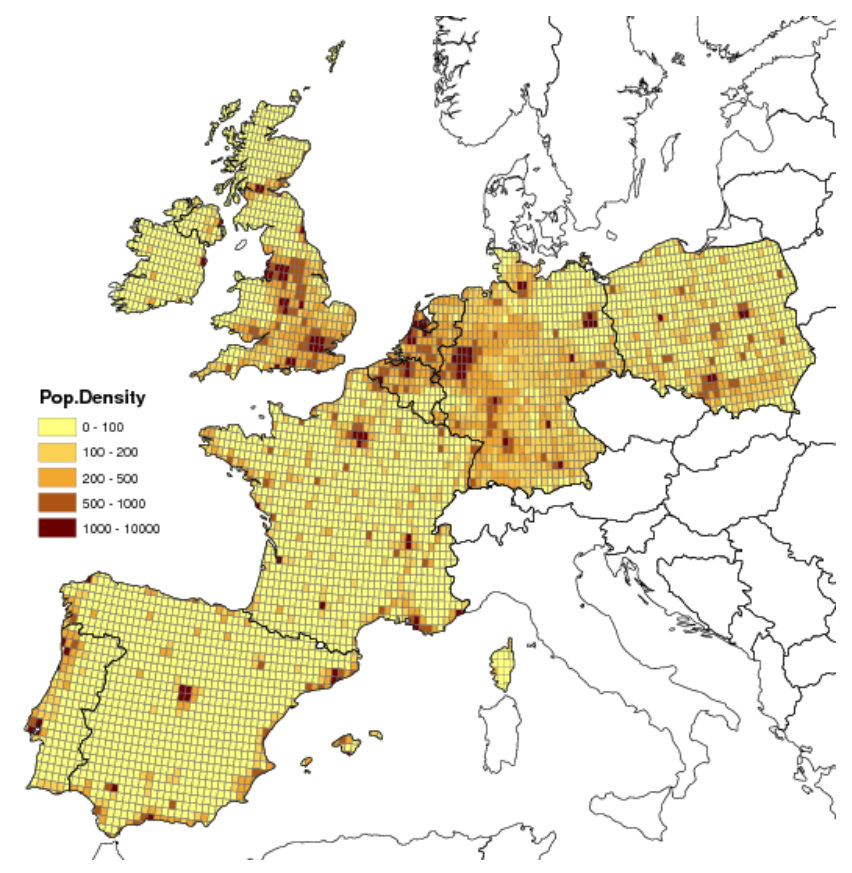

Fig. 1. Population density on a $0.25^{\circ} \times 0.25^{\circ}$ grid (source: CIESIN, 2005 ) is used as a proxy for insured values in the regions for which loss calculations were performed (unit: inhabitants per $\mathrm{km}^{2}$ ).

only during the $2 \%$ of days with highest wind speeds (also refer to Leckebusch et al., 2007; Pinto et al., 2007). The climate change signals are generally presented as differences between the mean values of the $20 \mathrm{C}$ and A1B periods, covering three to four decades each. The ensemble mean losses were calculated by applying the loss function directly to the simulated wind speeds of each individual model and averaging the losses of all ensemble members a posteriori.

\section{Extreme wind speeds and related losses estimated from GCM and RCM scenario simulations}

\subsection{Analysis of the GCM simulations}

\subsubsection{Extreme wind speeds}

The ensemble average of all GCMs shows a general agreement with the ERA40 reanalysis for both spatial patterns and absolute speed values (Fig. 3a, b), although biases are found in some individual models (Fig. 2a). The GCM ensemble displays systematically higher speed values in comparison to ERA40 over the Atlantic and the Mediterranean (approximately 1-2 $\mathrm{m} \mathrm{s}^{-1}$ ), whereas lower speed values (up to $4 \mathrm{~m} \mathrm{~s}^{-1}$ ) are found over land and parts of the Baltic region. All GCMs also reproduce the typical patterns of extreme wind speeds (here: 98 th percentile of WIMAX) in the European region, with maximum values over sea areas and lower values over continental areas. Over land areas, the highest wind speeds are found over northern parts of Western
(British Isles, northern France) and Central Europe (Benelux, Denmark, northern Germany and northern Poland) and also over parts of Scandinavia. Minimum speed values occur over terrain with a complex orography. FUB-EGMAM produces relatively high speed values also in the area of the Iberian Peninsula. Note that this model has the coarsest spatial resolution and uses sea grid boxes in this area to keep the Strait of Gibraltar opened. Thus, lower surface drag leads to higher near-surface wind speeds, disagreeing with the observationbased (reanalysis) data set.

Although the speed values in the individual models are similar in magnitude, there are some specific differences. For example, wind speeds in FUB-EGMAM are systematically higher than in ERA40 and the other models, whereas IPSLCM4 and CNRM-CM3 produce generally lower speed values. These differences can only be partly attributed to the different calculation of daily maxima (Sect. 2). The modelto-model differences in absolute wind speeds can be largely resolved by the use of relative thresholds for loss calculations in subsequent parts of this paper.

The ensemble mean of future climate simulations for the end of the 21st century (Fig. 3b) features a significant increase of extreme wind speeds over northern parts of Central and Eastern Europe and a decrease over the Mediterranean. Similar results are found in most of the individual GCMs (Fig. 2b), whereas the exact position of the maximum change is shifted slightly east- or westward in the individual ensemble members. The most different change pattern is found in the IPSL-CM4 simulation: here, the zone of significantly increased wind speeds has shifted north-eastward towards the northern Baltic region, whereas extreme wind speeds decrease over Western Europe. The characteristics of the ACC signals for the first half of the 21 st century are similar to those for the end of the 21 st century in all individual models, though magnitude and significance are mostly lower (not shown).

\subsubsection{Loss potential}

Insurance companies have to pay on average about 900 million $€$ per year in Germany alone as a consequence of storm losses to residential buildings (GDV 2006, 2009). On the basis of the German insurance data, a mean annual loss ratio of approximately $0.15 \%$ o $( \pm 0.12 \%$ inter-annual standard deviation) was assumed for recent decades (compare also Leckebusch et al., 2007; Pinto et al., 2007; Donat et al., 2010b). Despite model-specific differences in the wind climatologies and also specific decadal variability, realistic annual mean losses are simulated on the basis of output from the 20C runs (Table 2), supporting the applicability of the GCMs for loss estimates. The simulations with ECHAM5 and HadGEM1 show mean loss ratios that are closest to the insurance data (between 0.14 and $0.16 \%$ ). The inter-annual standard deviation of annual losses is too low in all models except DMI-ECHAM5, which produces a mean loss ratio 
a)
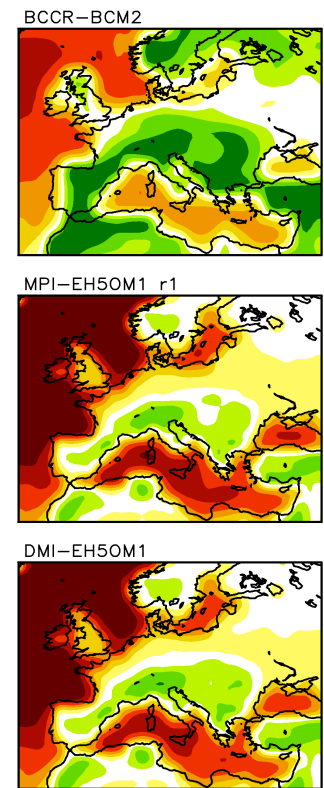

$\mathrm{BCCR}-\mathrm{BCM} 2$

b)

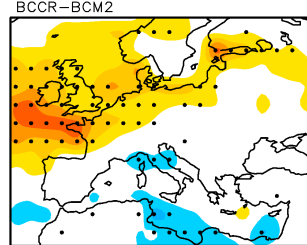

MPI-EH5OM $1 \mathrm{r} 1$

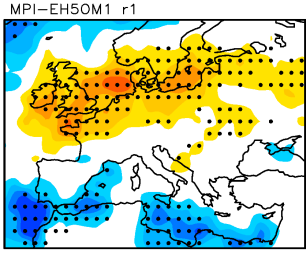

DMI-EH5OM1

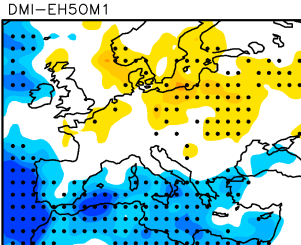

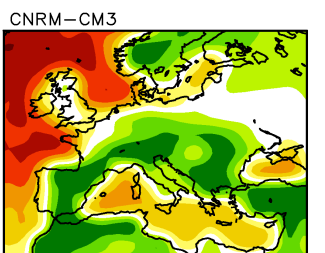

MPI-EH5OM1

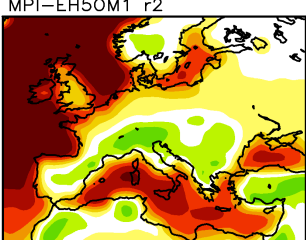

HC-HadGEM 1

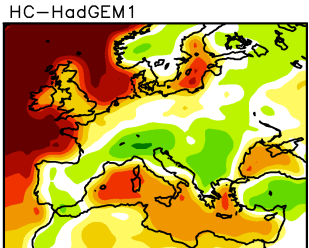

CNRM-CM3
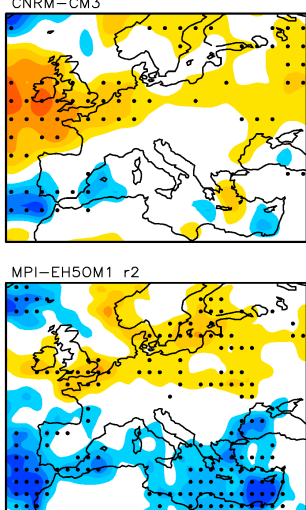

HC-HAdGEM

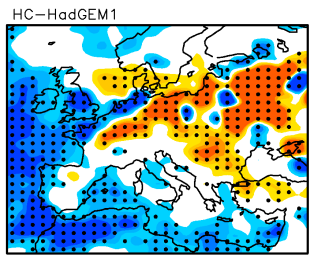

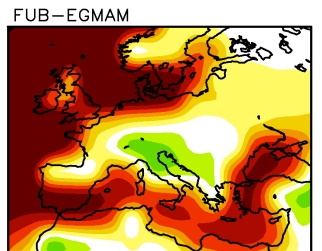

MPI-EH5OM1 $r 3$

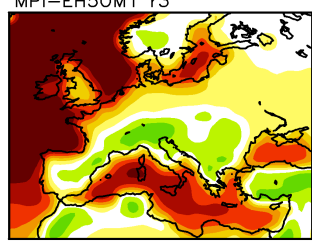

IPSL-CM4
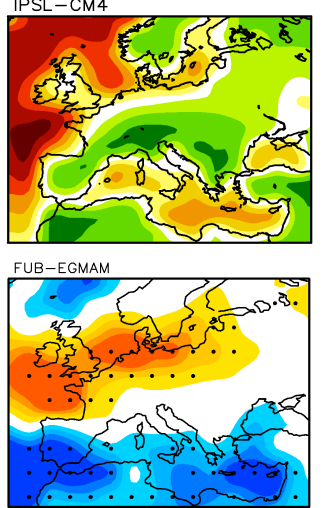

MPI-EH5OM1 $\mathrm{r} 3$

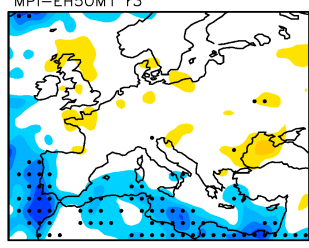

IPSL-CM4

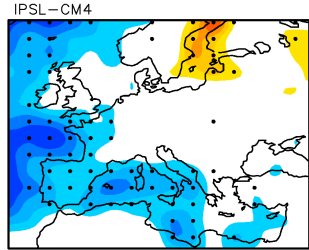

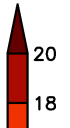
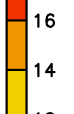

12
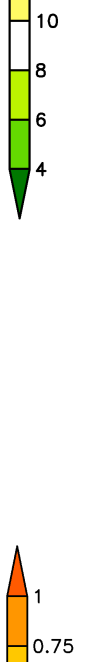

$-0.5$

$-0.25$

$-0.25$

$-0.5$

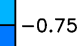

Fig. 2. 98th percentile of daily maximum wind speeds (WIMAX) in the GCM simulations. (a) Absolute values for 20C (generally 19612000, unit: $\mathrm{m} \mathrm{s}^{-1}$ ), (b) changes for A1B (2071-2100) relative to 20C (1961-2000): coloured areas indicate the magnitude of change (unit: $\mathrm{m} \mathrm{s}^{-1}$ ), statistical significance above 0.95 is indicated by black dots (Student's t-test).

and standard deviation that are closest to the insurance data. Losses calculated from the other models display a too low inter-annual variability compared to the observed insurance loss data.

With respect to the storm losses in the ACC simulations for the end of the 21 st century, considerable differences between the individual ensemble members are apparent, particularly for the case of no adaptation (Appendix, Table A1a). Considering area averages for individual countries, the largest changes are found for Germany, with eight out of nine ensemble members showing enhanced risk of mean loss, up to $+87.1 \%$ (HadGEM1). Only losses calculated from the DMI-ECHAM5 simulation show slightly decreased values $(-6.2 \%)$. In the ensemble average (Fig. 4, upper row), the annual mean loss ratio for Germany rises by $37.7( \pm 31.0) \%$. This increase goes along with an increased standard deviation of the annual losses in seven of the nine simulations and also in the ensemble mean. The increase of inter-annual variability (measured in terms of standard deviation of annual loss values) is primarily caused by individual years with extremely high losses, partly due to single, exceptionally strong events (Leckebusch et al., 2008a), which do not occur in the 


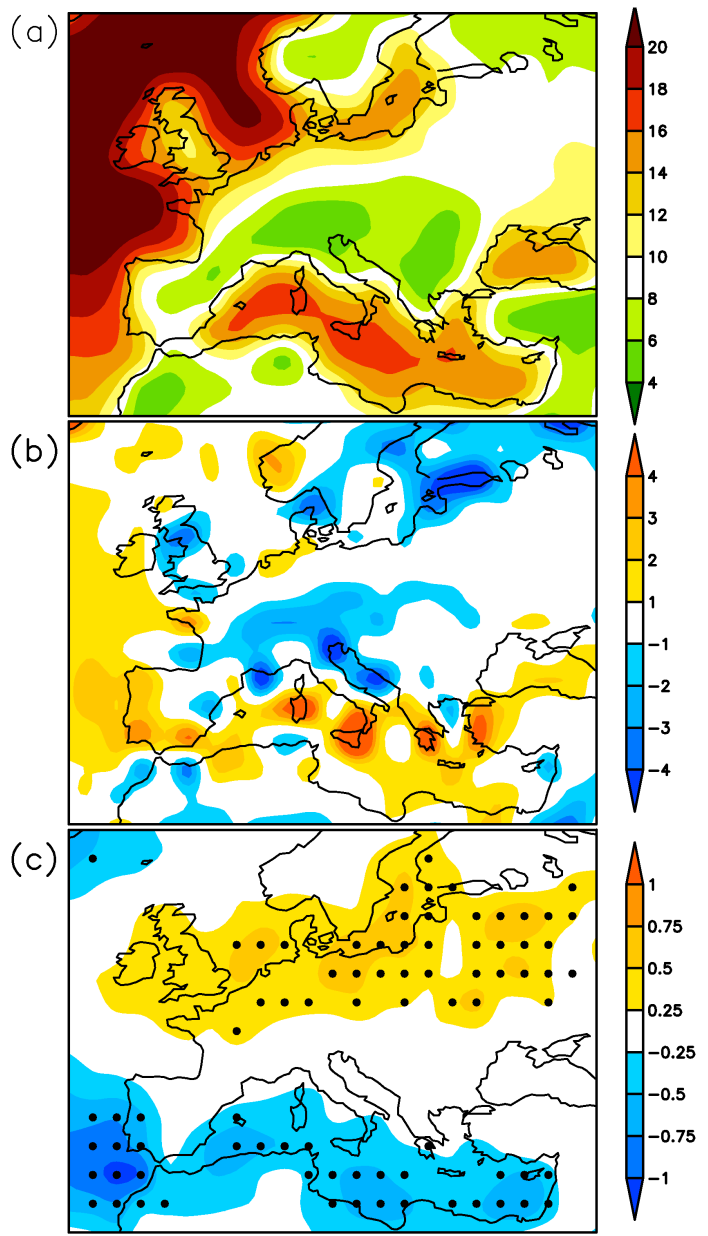

Fig. 3. Ensemble mean of 98th percentile of WIMAX in the GCM simulations. (a) Absolute values for 20C (1961-2000, unit: $\mathrm{m} \mathrm{s}^{-1}$ ), (b) anomaly GCM ensemble (20C) relative to ERA40 (unit: $\mathrm{m} \mathrm{s}^{-1}$ ), (c) changes for A1B (2071-2100) relative to 20C (19612000): coloured areas indicate the magnitude of change (unit: $\mathrm{m} \mathrm{s}^{-1}$ ), statistical significance above 0.95 is shown by black dots (Student's t -test)

GCM control periods. Thus, the increase of the inter-annual standard deviation might be even more relevant for impact assessments than changes in mean losses.

In the future climate simulations, France is affected by higher extreme wind speeds in its northern areas and lower extreme wind speeds in the Mediterranean region (Fig. 3b), partly offsetting each other when country-wide losses are calculated. Consequently the calculated increase of loss for France is small compared to that for other Western and Central European countries. In the average of all simulations, losses rise by $9.0( \pm 13.2) \%$, with slightly increased interannual variability. Of the nine ensemble members, seven reveal an increased risk, whereas two show slightly lower storm losses.
Table 2. Mean annual loss ratios for Germany and interannual standard deviation (STD) as provided by the German Insurance Association (GDV) and calculated from the ERA40 reanalysis and the 20C GCM simulations (unit: \%o). The bottom row displays GCM averages \pm inter-model standard deviations from the values shown in the preceding nine rows.

\begin{tabular}{lcc}
\hline & MEAN & STD \\
\hline GDV & 0.15 & 0.12 \\
ERA40 WIMAX & 0.15 & 0.10 \\
ERA40 GUST & 0.14 & 0.10 \\
BCCR-BCM2 & 0.12 & 0.08 \\
CNRM-CM3 & 0.11 & 0.04 \\
DMI-ECHAM5 & 0.15 & 0.12 \\
FUB-EGMAM & 0.12 & 0.06 \\
IPSL-CM4 & 0.12 & 0.07 \\
MPI-ECHAM5 run1 & 0.15 & 0.09 \\
MPI-ECHAM5 run2 & 0.16 & 0.10 \\
MPI-ECHAM5 run3 & 0.14 & 0.09 \\
METO-HC-HadGEM1 & 0.14 & 0.09 \\
GCM-Ensemble mean & $0.13 \pm 0.02$ & $0.08 \pm 0.02$ \\
\hline
\end{tabular}

Also for the BeNeLux area, seven of the nine ensemble members show an increased loss potential of up to $+50.4 \%$ (CNRM-CM3); the other two GCM simulations yield a slight decrease of about $-4 \%$. In the ensemble average, mean annual losses increase by $+17.6( \pm 21.2) \%$. Cumulated losses in the UK and Ireland rise by $+17.4( \pm 32.3) \%$ for the ensemble mean. Seven of the nine ensemble members show increases in loss for this region. The two models simulating reduced extreme wind speeds over Western Europe (HadGEM1, IPSL-CM4, cf. Fig. 2b) also feature considerably lower loss values.

A significant increase in extreme wind speed values was found over eastern Central Europe in the ACC simulations (Fig. 3b). In Poland, seven of the nine ensemble members feature enhanced risk of loss, and the ensemble mean shows an increase of mean annual losses by $12.1( \pm 18.3) \%$.

For the Iberian Peninsula (where reduced extreme wind speeds were simulated), seven ensemble members show decreased losses, and two have slight increases. The ensemble average of mean annual losses drops by $-10.1( \pm 10.0) \%$ in this area.

The four simulations with the ECHAM5 model reveal considerably different loss changes (Table A1a). Comparison of the individual ECHAM5 signals with the other models does not suggest any bias in the ensemble results due to the inclusion of multiple runs from this particular model. Nevertheless, we recalculated the ensemble mean loss changes, including only one simulation of each GCM. Thus, four different ensembles of six different GCMs can be constructed (each containing either realisation 1, 2 or 3 of MPI-ECHAM5 or the DMI-ECHAM5 run). If only 
a)

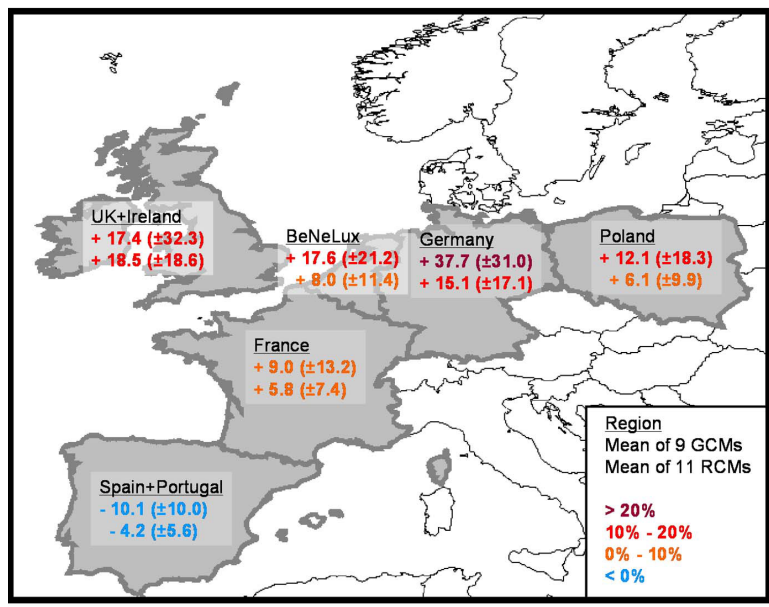

b)

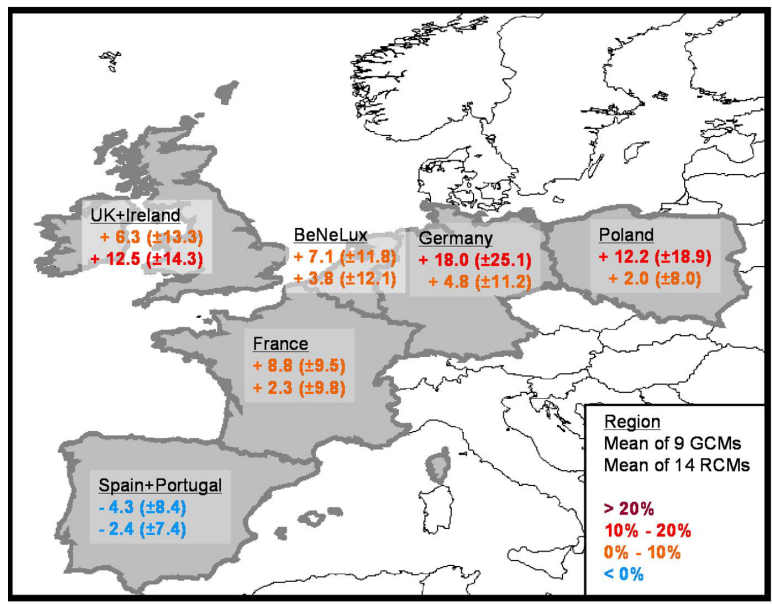

Fig. 4. Relative changes (unit: \%) of mean annual storm loss potential based on the GCM (upper row) and RCM (bottom row) simulations for the end (a) and middle (b) of the 21st century compared to recent climate conditions (20C, 1961-2000). Values in parentheses are inter-model standard deviations. (a) End of 21C (20712100), based on 9 GCM and 11 RCM simulations, (b) middle of 21C (2021-2050), based on 9 GCM and 14 RCM simulations.

one of these simulations is included in the ensemble mean calculation, the results are not much different from those of the larger ensemble, although there are some modifications with respect to the magnitudes of the ensemble mean changes. For example, the modified ensemble mean change signals for losses in Germany range between $+41.4 \%$ (including the DMI run) and $+51.2 \%$ (including MPI run1). Increased losses between $14.3 \%$ (including MPI run2) and 23.2\% (including MPI run1) are found for UK and Ireland; for the BeNeLux region, for example, the different ensemble results range between $+14.9 \%$ (including MPI run3) and $+22.3 \%$ (including MPI run 1 ). Thus, the large spread of possible changes between the different realisations of this particular model, comparable to the spread of changes based on the different GCMs, justifies the inclusion of all available simulations, especially as no evidence of bias was found. This larger ensemble size enables a more reliable estimate of the robustness of the identified changes, as it samples a larger number of realisations with regard to the internal variability.

Future loss changes are distinctly lower in the case of adaptation (i.e., the threshold for loss occurrence is adapted to the future wind climate, so that at each grid point it is again the $2 \%$ strongest wind events that cause losses; Appendix Table A1b). For Germany, for example, changes in the different ensemble members range between $+16.8 \%$ (IPSL-CM4) and $-22.6 \%$ (DMI-ECHAM5). In the ensemble mean, loss changes are small (up to $2 \%$ ) for Germany, France, BeNeLux and UK with Ireland, although increased inter-annual variability of losses is still found for Germany. Mean losses over Poland decrease by $6.5 \%$, but over the Iberian Peninsula they increase by $6.5 \%$, with increased losses found in eight of the nine ensemble members. Note that owing to the reduction of extreme wind speed in this region, the threshold for loss is also reduced when using the future percentile. Thus, the adaptation approach would correspond to an adaptation to weaker building structures here.

The detected changes for the first half of the 21st century (2021-2050) mostly show the same characteristics as the changes for the end for the 21st century (upper row in Fig. $4 \mathrm{~b}$ for loss changes without adaptation). For most regions, the magnitude of the ensemble mean signal is lower compared to the signal for the end of the 21 st century, although a large variability between the ensemble members is apparent (Appendix Table A1c).

With regard to the individual ensemble members, the results demonstrate the high decadal-scale variability in the occurrence of severe wind storms in the different realisations. Some of the loss potential change signals do not seem to scale proportionally with the GHG forcing because the identified changes include both internal variability and response to ACC. The MME of simulations samples the different phases of internal variability apparent in the individual realisations. Hence, the MME approach helps to identify the "pure" effect of the GHG forcing, assuming that the uncertainty due to internal variability is cancelled out.

\subsection{Analysis of the RCM scenario simulation}

\subsubsection{Extreme wind speeds}

Patterns of the 98th percentile of WIMAX, as produced by the GCM-driven RCM simulations for the 20C period, do not show major deviations from the reanalysis-driven runs (Fig. 5a, compare Donat et al., 2010b). The model-specific characteristics (such as systematic biases in absolute speed values and anomalies over mountainous regions) discussed in the previous study for the ERA40-driven simulations are almost identical with those originating from the (GCM-driven) $20 \mathrm{C}$ scenario simulations.

In the RCM future scenario simulations (Figs. 5b and $6 a, b)$, the ensemble mean shows significantly higher extreme wind speeds, particularly over Western Europe and in the 
a)

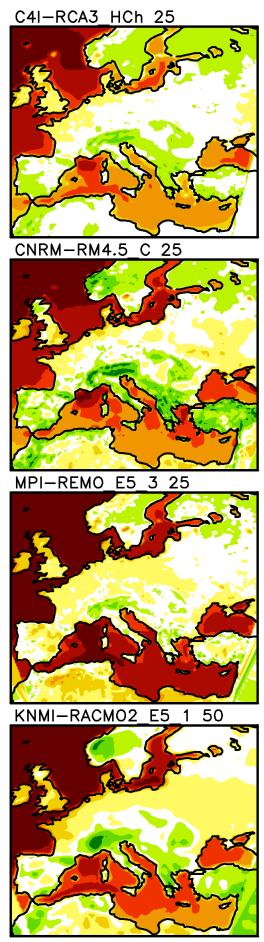

b)

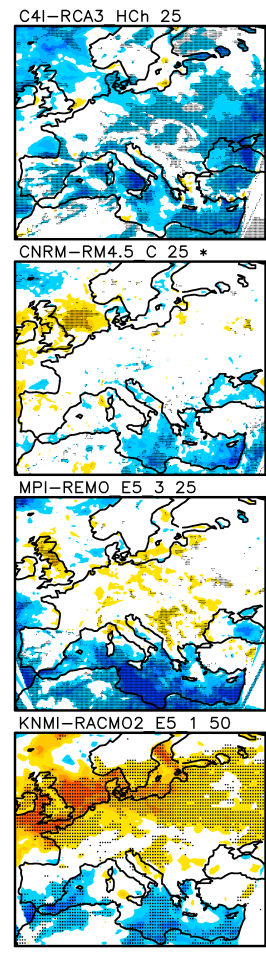

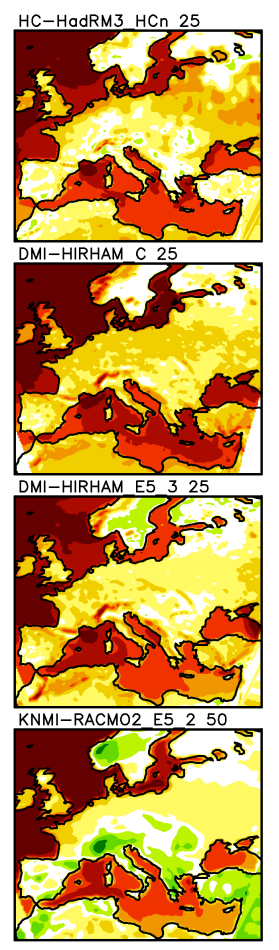
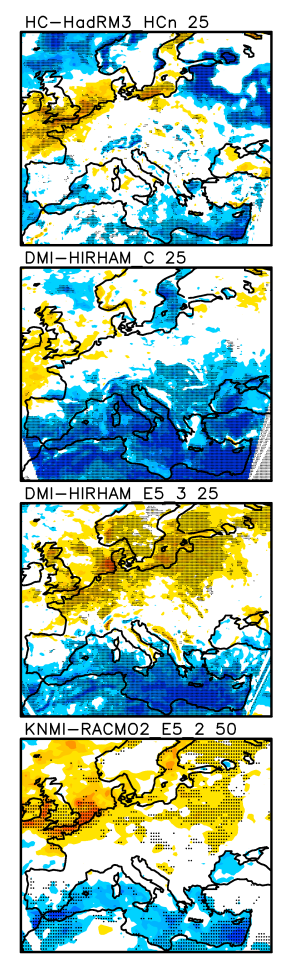
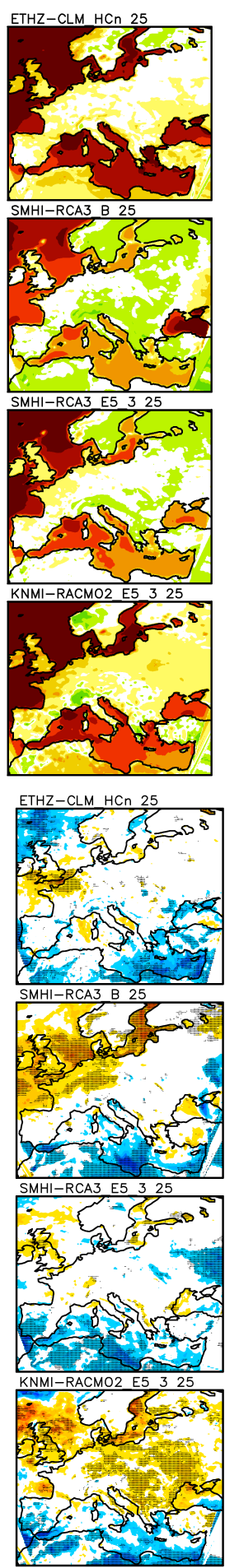
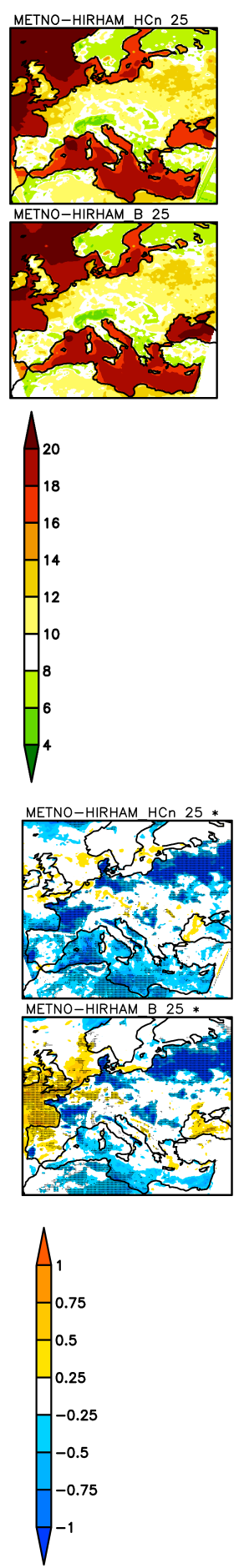

Fig. 5. 98th percentile of daily maximum wind speeds (WIMAX) in the RCM simulations. 1st row: driven by the (different) HadCM3 simulations, 2nd row: driven by CNRM-CM3 or BCCR-BCM2, 3rd row and 4th row: driven by MPI-ECHAM5 (run 1, 2 or 3). (a) Absolute values for the 20C period (1961-2000), (b) projected changes for 98th percentile of WIMAX in the RCM simulations; all results are for the future period 2071-2100, except for METNO_HIRHAM_HCn*, METNO-HIRHAM_B* and CNRM-RM4.5_C* (only integrated until 2050) changes are presented for the period 2021-2050. Magnitude of change is shown by coloured areas (unit: $\mathrm{m} \mathrm{s}^{-1}$ ), black dots indicate statistical significance above 0.95 (Student's t-test). 


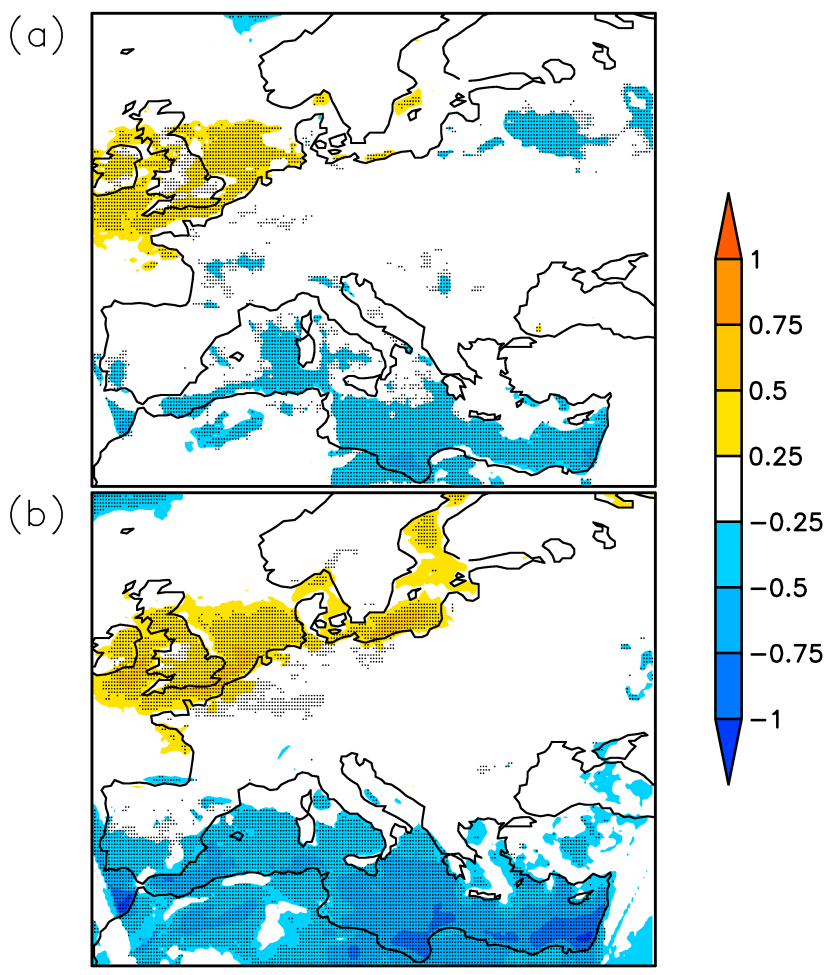

Fig. 6. RCM ensemble mean of projected changes for the 98th percentile of WIMAX in the future scenario simulations. Magnitude of changes is shown by coloured areas (unit: $\mathrm{m} \mathrm{s}^{-1}$ ), black dots indicate statistical significance above 0.95 (Student's t-test). (a) A1B (2021-2050) - 20C, (b) A1B (2071-2100) - 20C.

North Sea and Baltic Sea regions; reduced wind speeds occur over the Mediterranean. These are also common features in the majority of the RCMs. While relatively smooth change patterns are found in the GCM simulations (Sect. 3.1), the signals in most individual RCMs appear noticeably spotty over continental areas. These patterns seem to offset each other in the ensemble mean, and hence the accumulated changes over Central Europe are comparatively lower than for most of the individual models and the GCM ensemble. Although change patterns are similar when driven by the same GCM, there is a considerable spread in the magnitudes of change, pointing at the uncertainty related to the choice of a specific RCM. Note, for example, the differences between the four simulations driven by ECHAM5 run3 (Fig. 5b, third and fourth row) and also remember that this particular driving run displays only weak changes (Fig. $2 b$, middle row, right panel).

Ensemble mean change patterns for the middle of the 21st century (Fig. 6a), as for the GCM results, correspond well to the patterns for the end of $21 \mathrm{C}$ (Fig. 6b), whereas the significance of the signals is considerably higher for the later period. Note that three more simulations were included in the ensemble for the earlier period than in the corresponding ensemble for the end of $21 \mathrm{C}$ because CNRM-RM4.5_C,
METNO-HIRHAM_B and METNO-HIRHAM_HCn were only integrated until 2050. However, the picture is similar if ensemble means are computed for both periods using the same 11 simulations.

\subsubsection{Loss potential calculated from the RCM simulations}

Changes in storm loss potential from the RCMs correspond in general to the changes detected from the GCM outputs, although for most regions the mean relative changes are slightly smaller in the RCM ensemble (Fig. 4, compare bottom and top rows). Again there are considerable differences between the individual ensemble members (Appendix Table A2).

Following the no-adaptation approach, the RCM ensemble mean storm losses in Germany are estimated to increase by $15.1 \%$ (with a standard deviation between the different simulations of $17.1 \%$ ) by the end of 21C. For France, the ensemble mean change is $+5.8( \pm 7.4) \%$, for UK plus Ireland $+18.5( \pm 18.6) \%$, for BeNeLux $+8.0( \pm 11.4) \%$, for Poland $+6.1( \pm 9.9) \%$, and for the Iberian Peninsula $-4.2( \pm 5.6) \%$. Again a noticeable increase in inter-annual variability of losses is evident, particularly for Germany, Poland, BeNeLux and UK+IRE.

Analysis of different RCMs driven by the same GCM simulation reveals that despite identical large-scale driving, dynamical downscaling may increase the spread of possible results considerably. For example, loss changes between $+33.6 \%$ and $-4.5 \%$ are obtained for the four RCM runs driven by ECHAM5_run3, whereas the driving GCM run displays an increase of $+17.0 \%$. One RCM simulation shows a considerably stronger increase (KNMI-RACMO2_E5_3), two realisations (MPI-REMO_E5_3 and SMHI-RCA3_E5_3) show only small loss changes, and in the DMI-HIRHAME5_3 run, the calculated loss change is almost identical with the GCM signal. Thus, with respect to the large spread, the average loss change of the four RCM runs is similar $(+12.4 \%)$ to the GCM signal but still about $30 \%$ lower. Thus, further analysis of the impact of regional downscaling on the spread of climate change signals seems to be justified and necessary but is beyond the scope of this study.

Note that, for all regions except UK and Ireland, the magnitudes of the RCM ensemble mean changes were considerably smaller than the magnitudes of changes in the GCM ensemble. This might partly be explained by the ensemble setup: for example, the GCM simulations showing the largest changes were not used to drive RCM simulations (Tables 1a, c and Sect. 2). In addition, four RCM runs were driven by different perturbed-parameter experiments with the HadCM 3 model; daily maximum wind speeds from these experiments were not available for this study and so could not be included in the GCM ensemble. Nevertheless, the phenomenon of comparatively smaller change magnitudes in the RCM ensemble is still present if, first, the GCM 
ensemble mean contains only those GCM simulations that were used for downscaling and, second, the RCM ensemble contains only those RCM simulations where the driving GCM simulation is available. However, in some cases (e.g., KNMI_RACMO2_E5_3) even stronger RCM signals can be found in comparison to the driving GCM. Further studies are necessary to understand the differences between the changes detected from large-scale and regional models.

Ensemble mean changes for the first half of $21 \mathrm{C}$ (Fig. 4b, bottom row) were small (below 5\%) for most of the regions considered; a large signal, $+12.5( \pm 14.3) \%$, was found only for UK+IRE. As already established for the GCM simulations, detected changes are small if adaptation of the loss threshold to the future climate is taken into account (not shown), demonstrating the value of timely strategic action.

\subsubsection{Does the use of RCM gust wind speeds modify the results?}

Gust wind speed estimations (implemented as online model diagnostics) are also available from a subset of the RCM simulations. The greatest damage in the "real world" is generally caused by severe wind gusts; Rockel and Woth (2007) documented that wind speeds exceeding $20 \mathrm{~m} \mathrm{~s}^{-1}$ (8 Bft.) are generally not produced by RCMs without a gust parameterisation. However, as the loss model applied here uses a relative threshold for the occurrence of losses, exceedance of a specific absolute wind speed should not be necessary for a realistic loss calculation, assuming a correspondence between extreme sustained winds and gusts. With respect to the reproduction of observed losses, Donat et al. (2010b) demonstrated that the temporal correlation of losses calculated from GUST is generally not higher than for losses based on WIMAX.

The above results for extreme wind speeds and loss potential largely agree with those obtained using GUST. The patterns of the ACC signals for the 98th percentile of GUST correspond well to the change patterns for WIMAX, although the magnitudes of change and significance tend to be stronger for some simulations using GUST (C4IRCA3_HCh, ETHZ-CLM_HCn and SMHI-RCA3_B, not shown). For the other five simulations providing GUST (KNMI-RACMO2_E5_1,2,3, MPI-REMO_E5_3 and SMHIRCA3_E5_3), change patterns and magnitudes are very similar to WIMAX.

In general, changes in loss potential based on GUST are comparable to those based on WIMAX. Again, C4IRCA3_HCh and ETHZ-CLM_HCn display somewhat larger signals for most regions compared to WIMAX, whereas the changes detected in the other simulations are mostly similar to (or sometimes even slightly smaller than) the corresponding WIMAX results. Remarkably, loss changes for MPIREMO_E5_3 based on GUST are almost equal to changes based on WIMAX in all regions. This was also found for the SMHI-RCA3_E5_3 run in all regions except IBERIA. The ensemble mean loss changes are generally comparable to the RCM mean changes based on WIMAX (Fig. 4). In summary, we find no systematically altered results if losses are calculated on the basis of wind gusts instead of WIMAX.

\subsection{Multi-model combinatorics: uncertainty of ACC loss potentials considering all possible model combinations}

\subsubsection{The multi-model combinatorics approach}

MME studies are affected by a certain level of arbitrariness. For example, the construction of an ensemble is determined by the availability of model simulations. As the individual simulations produce ACC signals with different magnitudes and even different signs (Sects. 3.1 and 3.2), the MME change will depend on the models included. Here, the influence of different model combinations on the loss potential changes is investigated systematically for the first time by considering all possible model combinations in a multimodel combinatorics approach. The range of the resulting ACC signals allows an estimation of the (un-)certainty of projected future changes. The idea behind this approach is to use all information included in the MME. For this study, the composition of the MME was defined by the models included in the ENSEMBLES project (Tables 1a, b).

Using the 9 available GCM simulations, there are in total 511 different possibilities of calculating (sub-) ensembles including 1 to 9 individual ensemble members: 9 single models, 36 combinations of either 2 or 7 models, 84 (of 3 or 6), 126 (of 4 or 5), 9 combinations of 8 models and 1 ensemble containing all 9 simulations. Additionally, 14 RCM scenario simulations are available until 2050 (and 11 until 2100), allowing 16383 (or respectively 2047) different RCM combinations. Thus, in total, 23 individual (GCM or RCM) ACC signals for the first half of $21 \mathrm{C}$ and 20 for the end of $21 \mathrm{C}$ are available, enabling 8388607 different model combinations for the earlier and 1048575 for the later period. The consideration of all possible model combinations can be seen as an "ensemble of (sub-) ensembles". Basically, this idea of assessing the uncertainty of the projected changes is related to the principle of bootstrapping (Efron, 1979), which is applied to gain information about characteristics (e.g., quantiles) of an unknown theoretical distribution. However, whereas bootstrapping generally considers different limited samples to assess the characteristics of a basic population, the approach presented here accounts for all possible solutions that can be constructed from the ensemble of models.

A limitation might arise from the fact that the different (sub-) ensembles are not necessarily independent of each other. Each simulation is included in several (sub-) ensembles, and some of the GCM simulations are used for driving the RCM simulations (and are thus included in the RCM results). In addition, different models are not completely independent, as some share common components or modules. All these factors make it difficult to estimate, for 
example, the degrees of freedom of the sample of possible future changes. Nevertheless, if only different subsets of simulations were available for this study, all these results are possible and thus have to be included in the considerations. Moreover, even different realisations with the same model display different change signals (Sect. 3.1), and the RCMs have been shown to increase the spread of possible results, including some that are fundamentally different, even compared to their driving GCMs (Sect. 3.2). With this approach, a complete sample based on the different sub-ensembles is obtained, making use of all information included in the ensemble of models. Assuming that the sample which is constructed from the available models included in the study is representative for a sample based on all existing climate models, this methodology allows an estimation of the range of expected future changes.

\subsubsection{Uncertainties in projected storm losses}

We have focussed on the ACC signals without adaptation of the loss threshold (Appendix Tables A1, A2). The range of possible changes based on the GCM and RCM simulations for the end of $21 \mathrm{C}$ is presented for the different regions (Fig. 7). Histograms of relative loss changes of the different sub-ensembles were calculated (in 2\%-steps), and the relative frequency of the different change magnitudes is displayed. The green curve summarises the results of the 511 GCM combinations (of 9 GCM simulations), the blue curve represents the $2047 \mathrm{RCM}$ sub-ensembles (of $11 \mathrm{RCM}$ simulations integrated until 2100), and the red curve comprises the results of the 1048575 combinations of all available GCM or RCM simulations. For each region, the red shaded area indicates a confidence interval where $90 \%$ of the signals between the 5th and the 95th percentiles are found. As each individual simulation is included in the same number of model combinations, the ensemble average of possible (sub-) ensembles has exactly the same value as the simple ensemble mean of all available models (Fig. 4).

It becomes obvious that the largest spread of ACC signals is found in Germany and the UK + IRE region. For Germany, the red curve comprising all combinations of available GCM and RCM simulations indicates a mean increase of loss potential of about $25.2 \%$, with the confidence interval of $90 \%$ of the possible solutions between $+15.1 \%$ and $+35.4 \%$. Corresponding estimates for other regions are: $\mathrm{UK}+\mathrm{IRE}+18.1 \%(+8.4$ to $+27.6 \%), \mathrm{BeNeLux}+12.3$ $(+5.7 \%$ to $+18.8 \%)$, Poland $+8.8 \%(+3.4 \%$ to $+14.2 \%)$. The narrowest ranges of possible results are found for France + $7.2( \pm 3.9) \%$ and IBERIA $-6.9( \pm 3.2) \%$. As already discussed in Sect. 3.2, for most regions (except for UK + IRE) the magnitude of the changes on the basis of the GCM ensemble (green curves in Fig. 7) is larger than for the RCM ensemble (blue curve). Note, however, that those GCMs displaying outlier signals were not used to drive RCMs. GCM changes tend to exceed those for the RCM ensembles, not only in cases where all available models are considered. If the ensembles are restricted to those GCMs used for downscaling (and available for this study: CNRM-CM3, BCCRBCM2, ECHAM5) in comparison to the connected RCM runs, different magnitudes are still obvious for the (reduced) GCM- and RCM-ensembles (not shown). The uncertainty range of the GCM-based results is, however, considerably reduced (and similar to the RCM range) if only those GCMs used for driving the RCMs are considered.

The uncertainty range estimated from all model combinations is considerably smaller than the inter-model standard deviation (Fig. 4), which is affected to a greater extent by outlier models. For example, considering only the change signals from the GCM simulations and the respective confidence interval of the range covering $90 \%$ of all 511 possible results (green curve in Fig. 7a), the mean increase for Germany is $37.7( \pm 19.7) \%$. By comparison, the signal was $37.7( \pm 31.0) \%$ if the inter-model standard deviation was used as the uncertainty measure (Sect. 3.1.2). Accordingly, narrower confidence intervals are also obtained for the other regions: the mean GCM-based loss change for BeNeLux is $+17.6( \pm 14.4) \%$, for France $+9.0( \pm 8.1) \%$, for Poland +12.1 $( \pm 11.5) \%$, for UK+IRE $+14.4( \pm 21.6) \%$, and for IBERIA $-10.1( \pm 6.3) \%$.

The mean changes for the period from 2021 to 2050 are generally smaller than those for the end of $21 \mathrm{C}$ (Appendix Fig. A1, in accordance with Tables A1c, A2b). For this earlier period, the widest spreads in the $8,388,607$ possible model combinations of all 23 ACC simulations were again found for Germany and UK+IRE, whereas the identified changes for France and IBERIA display the narrowest distributions. The magnitudes of the ensemble mean changes for this earlier period are between $40 \%$ (Germany, BeNeLux) and $70 \%$ (France, Poland), compared to the changes for the end of $21 \mathrm{C}$.

\section{Summary, discussion and conclusion}

Patterns of extreme wind speeds and related loss potential due to severe wind storms were investigated using the output of multi-model simulations with global and regional climate models. Potential future changes were analysed for different European regions according to the IPCC SRES A1B emission scenario. The GCMs and RCMs considered here reproduced the typical spatial patterns of extreme wind speeds well over the European region in the simulations of recent climate, even though some of the models displayed biases in absolute wind speeds. Realistic mean losses were obtained for calculations based on the 20C simulations; the inter-annual variability of simulated losses for Germany was about $30 \%$ lower in the ensemble mean than that observed from insurance loss data.

In the future climate simulations, most models and also the ensemble mean commonly featured an increase in extreme wind speeds over northern Central Europe and a decrease 

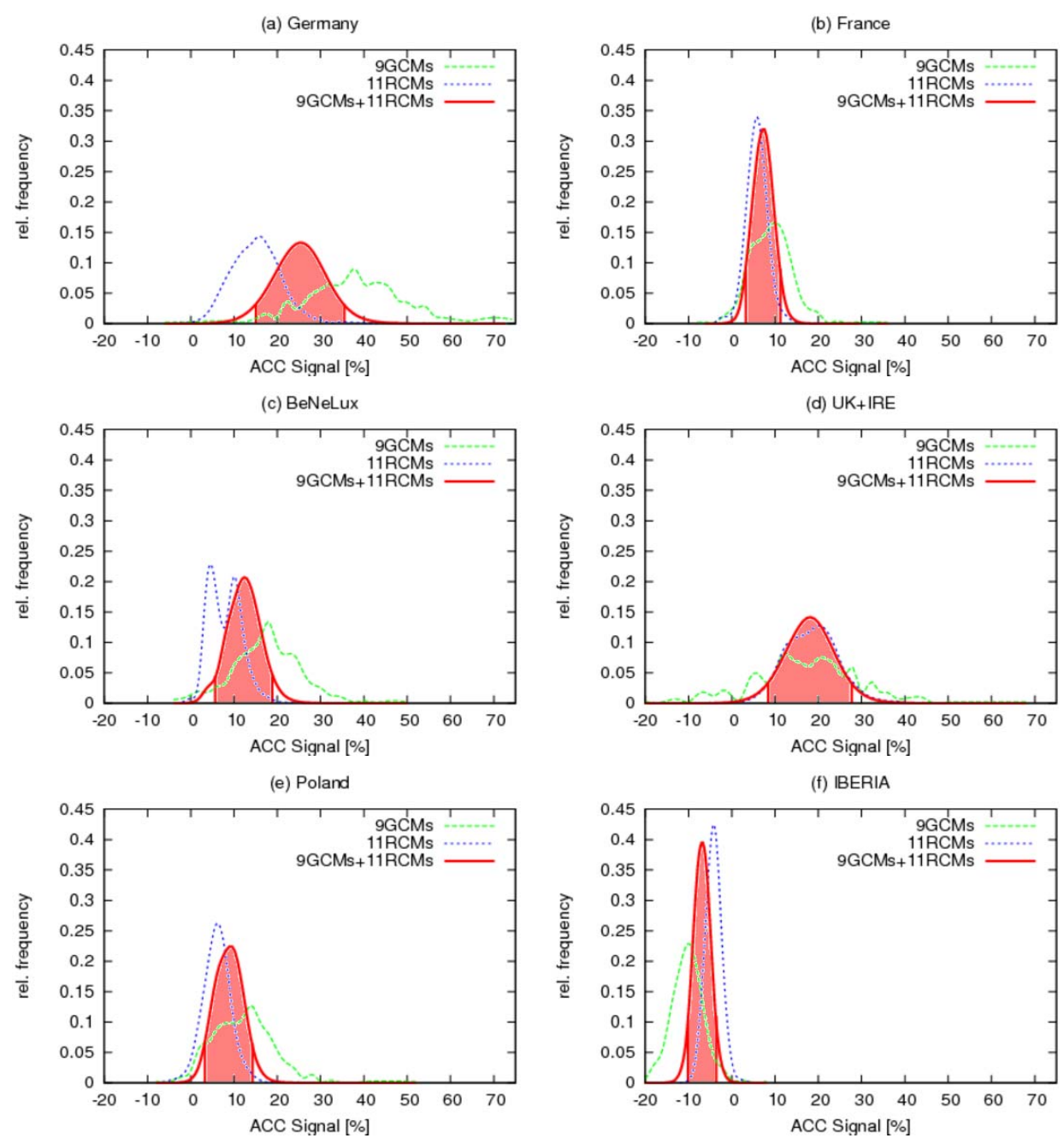

Fig. 7. Probability of loss potential changes for the future climate period end of 21C (2071-2100) compared to 20C (1961-2000) without adaptation of the loss threshold, based on all the possible model combinations of GCMs (green curve), RCMs (blue curve) and all the available GCM and RCM scenarios (red curve) simulations. The red shaded areas mark the range where $90 \%$ of the change signals (between 5th and 95th percentile) based on all model combinations are found.

over the Mediterranean region. Assuming that no adaptation takes place (and the loss-wind relation remains unaltered in a changing climate), the mean loss ratios also increased in the Western and Central European regions. In the ensemble mean, the loss potential in Germany at the end of 21C increased by $37.7 \%$ (15.1\%) according to the GCM (RCM) simulations considered in this study. Simulated losses also increased significantly by $12.1 \%(6.1 \%)$ over eastern Central Europe (e.g., over Poland). Mean losses for UK+IRE increased by $17.4 \%(18.5 \%)$, for France by $9.0 \%$ (5.8\%), and by $17.6 \%(8.0 \%)$ in the BeNeLux countries. In accordance with the reduction in extreme wind speeds, reduced storm loss risk was found over Southern Europe (e.g., for the Iberian Peninsula $-10.1 \%(-4.2 \%)$ in the GCM (RCM) ensemble). If adaptation to the changing wind climate was taken into account, the changes of calculated losses were generally small (ensemble mean changes below $5 \%$ for most regions considered).

However, there is a large spread in the results from the individual ensemble members, pointing to large variability in severe storm occurrence, even for different realisations with the same climate model. Central Europe, in particular, shows an increased inter-annual variability of losses, caused by single years with exceptionally high losses (Pinto et al., 2007). Characteristics of extremely severe storm events in future climate simulations will be investigated in future studies.

The spatial patterns of change in extreme wind speeds from RCMs have previously been shown to be close to the pattern of the driving GCM (Leckebusch et al., 2006). The same behaviour was found in this study. However, dynamical downscaling using RCMs is also shown to be an important source of uncertainty, increasing the spread in magnitude of 
possible results compared to the change signal from the driving GCM. For different RCMs driven by the same GCM simulation, comparable spatial change patterns of extreme wind speeds were found, although the magnitudes differ considerably. Consequently, the changes of loss potentials show strongly differing magnitudes despite identical large-scale forcing.

The most serious damage is generally caused by severe gusts, so it is often assumed that gust wind speeds may be more suitable for the calculation of storm losses than maximum wind speeds without gusts. However, a recent study using the same loss function as applied here found no evidence that losses calculated from GUST agree better with observed losses than losses calculated from WIMAX (Donat et al., 2010b). Moreover, this study shows comparable loss potential changes in future projections using both GUST (where available) and WIMAX.

The identified changes in the pattern of extreme wind speeds correspond to results from previous studies that also found significantly increased values over northern parts of Central and Western Europe and decreased values over Southern Europe (Leckebusch and Ulbrich, 2004; Leckebusch et al., 2006; Pinto et al., 2007; Gastineau and Soden, 2009). The increase in extreme wind speeds over Western and Central Europe is consistent with the increased activity of extreme cyclones identified over the eastern Atlantic/western European region in future climate simulations with the same GCM ensemble (Leckebusch et al., 2008b).

The magnitude of changes in loss potential is similar to the results in recent studies based on smaller MMEs (Leckebusch et al., 2007) or single model ensembles (Pinto et al., 2007). These studies also identified a large spread between the different GCMs and even different realisations with the same GCM. Whereas previous studies focused on loss changes in Germany and the UK, estimates here are for six regions in Central and Western Europe. Further, unlike previous studies, this study is based on a relatively large MME, allowing a more detailed estimation of the uncertainties of expected changes. The slightly different loss projections for the three ECHAM5 simulations in this study compared to Pinto et al. (2007) are due to the different population data sets applied. The population data in this study are at a finer resolution so as to be applicable for loss estimates based on RCMs.

Barredo (2010) suggested that observed recent upward trends of storm loss amounts are mainly driven by societal factors and can thus be explained by increasing economic and insured values. For the analysis of future loss potential in this study, societal factors affecting the loss change were explicitly excluded by assuming an unchanged population (a proxy for insured values) in the future periods compared to today. Further, the loss measure applied here takes into account the ratio between insured claims and totally insured values, thus normalising inflation. Consequently, assuming continuously increasing values for the next century, total monetary loss amounts might increase considerably more than those analysed here. In this study only the "pure" meteorological effect of anthropogenically induced climate change is analysed, which has to be recognised in addition to any societal trend. In Germany alone, given today's mean annual (insured) loss amounts of about 900 million $€$ for residential buildings, a meteorologically induced increase of loss potentials of about $25 \%$ (as derived from the model combinations in Sect. 3.3) would account for additional costs of approximately 225 million $€$ per year. Societal factors could further magnify these losses.

This study further demonstrates that relatively small changes in meteorological parameters may lead to considerable increases in risk. For storm losses, a non-linear relationship between wind speeds and losses is assumed, which contributes, in part, to the significance of loss changes. While the increase in absolute wind speeds is relatively low (e.g., up to $5 \%$ in the GCM ensemble for Central Europe), conspicuously higher losses are expected (e.g., approximately $37 \%$ in the GCM ensemble for Germany).

The magnitude of potential future changes in losses differs strongly between the different ensemble members, even for different realisations with the same GCM. Further, a comparison between the projected changes for the first half and the end of the 21 st century reveals fundamental differences for some ensemble members. Both phenomena - the large spread of ACC signals in the different simulations as well as the differences for the 2 future periods in some simulations indicate the large long-term variability in severe storm occurrence, which is partly related to decadal-scale atmospheric variability. Thus, future changes inferred from single models may be influenced by effects connected to this high variability and hence be misleading. Uncertainties due both to internal variability and to individual model formulations are sampled when using multi-model simulations and would tend to be cancelled out.

The ensemble of simulations also provides information permitting an estimation of the uncertainty of the results. Two different measures were used to evaluate this. One is the standard deviations of change signals across different simulations (Fig. 4), which were of the same order as the mean changes for most regions. These are strongly influenced by outliers, with some individuals displaying fundamentally different signals compared to the majority of models (Appendix Tables A1, A2). Alternatively, the range (as well as the probability) of possible changes is calculated by considering the results from all sub-ensembles that can be constructed from the available climate simulations. This yields a relatively symmetric distribution of possible changes around the ensemble mean and also enables probabilistic information to be given about the confidence in expected changes. For example, combining the detected loss potential changes from all available GCM and RCM simulations for the end of 21C for Germany yields a mean increase of $+25 \%$, with a $90 \%$ confidence interval of $+15 \%$ to $+35 \%$. 

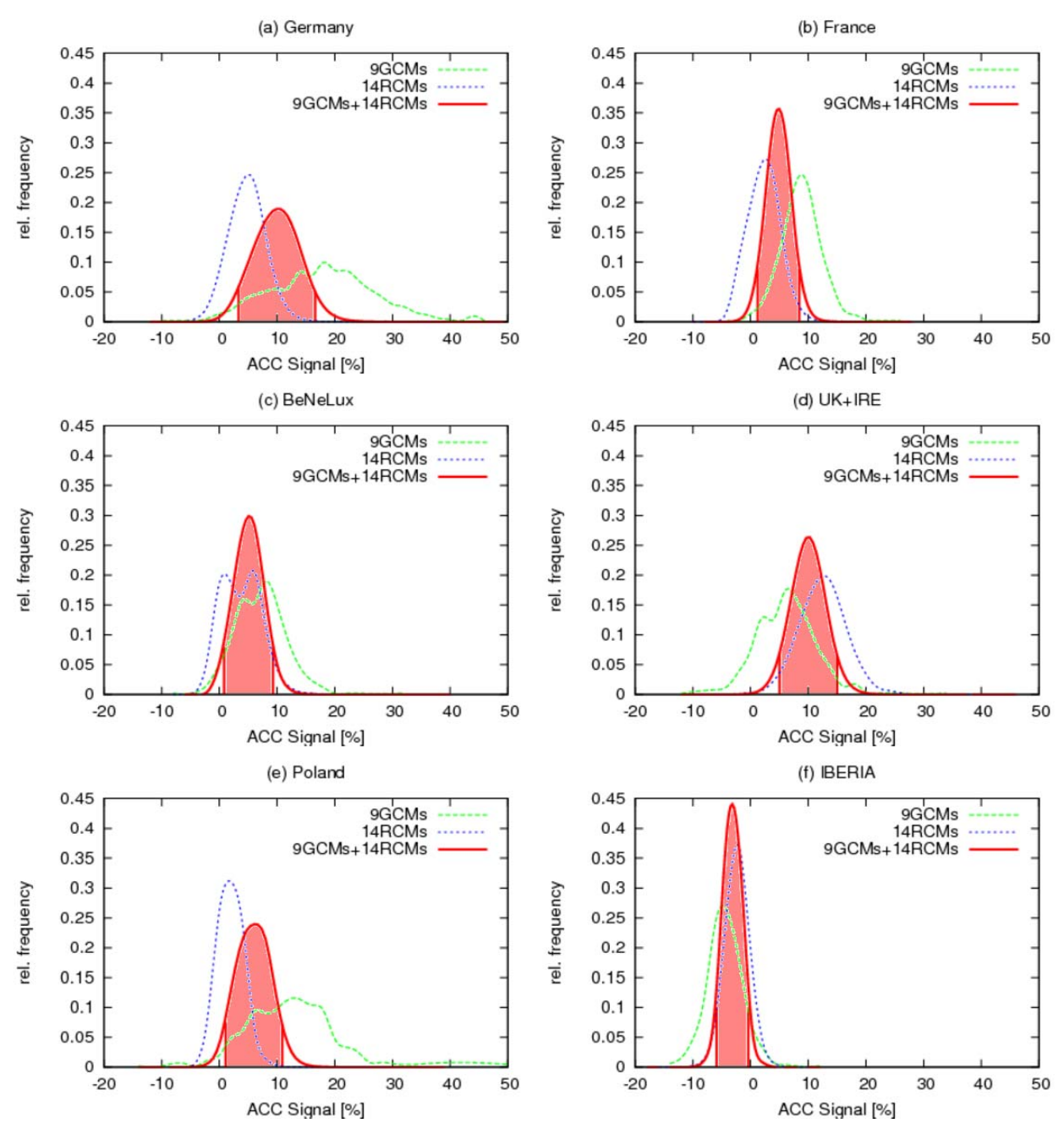

Fig. A1. Probability of loss potential changes for the future climate period in the middle of 21C (2021-2050) compared to 20C (1961-2000) without adaptation of the loss threshold, based on all possible model combinations of GCMs (green curve), RCMs (blue curve) and all available GCM and RCM scenario (red curve) simulations. The red shaded areas mark the range where $90 \%$ of the change signals (between 5th and 95th percentile) based on all model combinations are found.

Acknowledgements. This study was supported by the ENSEMBLES project, funded by the European Commission's Sixth Framework Programme through contract GOCE-CT-2003-505539. We particularly thank the modelling groups for performing the simulations, the DMI (Danish Meteorological Institute) for archiving the RCM results, and the DKRZ (German Climate Computing Centre) for archiving the GCM results. Thanks to the ECMWF, the DWD (German Weather Service) and the DKRZ for ERA40 data use and availability. We are grateful to three anonymous reviewers and to the editor Timothy Carter, whose constructive comments helped to focus the manuscript. Many thanks to Anne Beck (FU Berlin) and Lisa V. Alexander (Climate Change Research Centre, UNSW, Sydney) for their language revisions and corrections to the manuscript.

Edited by: T. Carter

Reviewed by: S. Goyette and two other anonymous referees

\section{References}

Barredo, J. I.: No upward trend in normalised windstorm losses in Europe: 1970-2008, Nat. Hazards Earth Syst. Sci., 10, 97-104, doi:10.5194/nhess-10-97-2010, 2010.

Bärring, L. and von Storch H.: Scandinavian storminess since about 1800, Geophys. Res. Lett., 31, L20202, doi:10.1029/2004GL020441, 2004.

Bengtsson, L., Hodges, K. I., and Roeckner, E.: Storm Tracks and Climate Change, J. Climate, 19, 3518-3543, 2006.

Brasseur, O.: Development and Application of a Physical Approach to Estimating Wind Gusts, Mon. Weather Rev., 129, 5-25, 2001.

Center for International Earth Science Information Network (CIESIN), Columbia University; and Centro Internacional de Agricultura Tropical (CIAT), Gridded Population of the World Version 3 (GPWv3): Population Density Grids, Palisades, NY: Socioeconomic Data and Applications Center (SEDAC), 
Table A1. ACC signal of simulated loss ratios in the individual GCMs. Relative changes for the future climate periods considered in this study compared to the 20C simulations are presented (unit: percent). For each region, the maximum and minimum changes of mean loss ratios (indicating the maximum spread of the ensemble) are highlighted using bold numbers.

\begin{tabular}{|c|c|c|c|c|c|c|c|c|c|c|c|c|}
\hline \multicolumn{13}{|c|}{ (a) 2071-2100 without adaptation } \\
\hline & \multicolumn{2}{|c|}{ Germany } & \multicolumn{2}{|c|}{ France } & \multicolumn{2}{|c|}{ UK } & \multicolumn{2}{|c|}{ Iberia } & \multicolumn{2}{|c|}{ Poland } & \multicolumn{2}{|c|}{ Benelux } \\
\hline & MEAN & STD & MEAN & STD & MEAN & STD & MEAN & STD & MEAN & STD & MEAN & STD \\
\hline BCCR-BCM2 & $51.5 \%$ & $26.6 \%$ & $19.7 \%$ & $1.6 \%$ & $4.6 \%$ & $-31.5 \%$ & $8.4 \%$ & $46.3 \%$ & $14.3 \%$ & $78.3 \%$ & $4.5 \%$ & $-3.0 \%$ \\
\hline CNRM-CM3 & $43.1 \%$ & $127.6 \%$ & $5.0 \%$ & $-58.7 \%$ & $50.9 \%$ & $134.3 \%$ & $-5.1 \%$ & $-43.1 \%$ & $-0.9 \%$ & $-39.0 \%$ & $50.4 \%$ & $280.7 \%$ \\
\hline FUB-EGMAM & $69.4 \%$ & $261.6 \%$ & $36.5 \%$ & $49.0 \%$ & $67.6 \%$ & $119.5 \%$ & $-17.5 \%$ & $-54.5 \%$ & $27.4 \%$ & $91.2 \%$ & $41.4 \%$ & $172.5 \%$ \\
\hline MPI-EH5OM1 r1 & $52.8 \%$ & $215.3 \%$ & $14.0 \%$ & $21.4 \%$ & $54.6 \%$ & $152.3 \%$ & $-10.5 \%$ & $-18.2 \%$ & $-7.6 \%$ & $-43.0 \%$ & $40.2 \%$ & $560.5 \%$ \\
\hline MPI-EH5OM1 r2 & $21.6 \%$ & $50.9 \%$ & $-3.0 \%$ & $-10.3 \%$ & $1.5 \%$ & $15.9 \%$ & $-12.5 \%$ & $-15.7 \%$ & $12.6 \%$ & $-9.7 \%$ & $18.8 \%$ & $88.5 \%$ \\
\hline MPI-EH5OM1 r3 & $17.0 \%$ & $63.5 \%$ & $9.8 \%$ & $107.3 \%$ & $4.5 \%$ & $6.2 \%$ & $0.8 \%$ & $103.2 \%$ & $4.8 \%$ & $51.4 \%$ & $-4.1 \%$ & $-44.6 \%$ \\
\hline DMI-EH5OM1 & $-6.2 \%$ & $-47.1 \%$ & $3.2 \%$ & $13.4 \%$ & $11.7 \%$ & $-4.4 \%$ & $-416.8 \%$ & $-17.6 \%$ & $3.9 \%$ & $-50.0 \%$ & $10.2 \%$ & $47.7 \%$ \\
\hline HC-HadGEM1 & $87.1 \%$ & $99.9 \%$ & $-7.6 \%$ & $-53.2 \%$ & $-22.1 \%$ & $-76.3 \%$ & $-24.2 \%$ & $-28.0 \%$ & $52.8 \%$ & $37.2 \%$ & $-4.3 \%$ & $-33.5 \%$ \\
\hline IPSL-CM4 & $3.4 \%$ & $-11.7 \%$ & $3.7 \%$ & $17.8 \%$ & $-16.5 \%$ & $-56.0 \%$ & $-13.3 \%$ & $-27.5 \%$ & $1.6 \%$ & $-9.5 \%$ & $1.3 \%$ & $19.9 \%$ \\
\hline Ensemble-Mean & $37.7 \%$ & $87.4 \%$ & $9.0 \%$ & $9.8 \%$ & $17.4 \%$ & $28.9 \%$ & $-10.1 \%$ & $-6.1 \%$ & $12.1 \%$ & $11.9 \%$ & $17.6 \%$ & $121.0 \%$ \\
\hline \pm inter-model STD & $\pm \mathbf{3 1 . 0 \%}$ & $\pm 101.2 \%$ & $\pm 13.2 \%$ & $\pm \mathbf{5 0 . 5 \%}$ & $\pm 32.3 \%$ & $\pm \mathbf{8 5 . 3 \%}$ & $\pm 10.0 \%$ & $\pm \mathbf{4 9 . 6 \%}$ & $\pm 18.3 \%$ & $\pm \mathbf{5 3 . 9 \%}$ & $\pm 21.2 \%$ & $\pm 195.1 \%$ \\
\hline \multicolumn{13}{|c|}{ (b) 2071-2100 with adaptation } \\
\hline & \multicolumn{2}{|c|}{ Germany } & \multicolumn{2}{|c|}{ France } & \multicolumn{2}{|c|}{ UK } & \multicolumn{2}{|c|}{ Iberia } & \multicolumn{2}{|c|}{ Poland } & \multicolumn{2}{|c|}{ Benelux } \\
\hline & MEAN & STD & MEAN & STD & MEAN & STD & MEAN & STD & MEAN & STD & MEAN & STD \\
\hline BCCR-BCM2 & $-6.5 \%$ & $-42.4 \%$ & $-12.3 \%$ & $-48.7 \%$ & $-21.6 \%$ & $-66.8 \%$ & $11.3 \%$ & $75.2 \%$ & $-2.0 \%$ & $10.1 \%$ & $-12.9 \%$ & $-59.4 \%$ \\
\hline CNRM-CM3 & $-10.8 \%$ & $-9.6 \%$ & $-15.2 \%$ & $-76.1 \%$ & $-3.7 \%$ & $-8.1 \%$ & $11.8 \%$ & $-9.9 \%$ & $-15.4 \%$ & $-69.2 \%$ & $4.8 \%$ & $36.5 \%$ \\
\hline FUB-EGMAM & $12.5 \%$ & $117.1 \%$ & $7.0 \%$ & $-1.7 \%$ & $21.6 \%$ & $35.8 \%$ & $3.7 \%$ & $-27.1 \%$ & $1.1 \%$ & $3.9 \%$ & $9.1 \%$ & $52.6 \%$ \\
\hline MPI-EH5OM1 r1 & $7.0 \%$ & $102.6 \%$ & $-3.9 \%$ & $-26.7 \%$ & $6.3 \%$ & $40.0 \%$ & $0.7 \%$ & $6.9 \%$ & $-23.0 \%$ & $-65.3 \%$ & $15.3 \%$ & $321.0 \%$ \\
\hline MPI-EH5OM1 r2 & $-1.8 \%$ & $12.1 \%$ & $-7.8 \%$ & $-16.1 \%$ & $-16.1 \%$ & $-17.0 \%$ & $0.5 \%$ & $13.2 \%$ & $-3.9 \%$ & $-33.0 \%$ & $5.2 \%$ & $28.2 \%$ \\
\hline MPI-EH5OM1 r3 & $9.5 \%$ & $54.4 \%$ & $2.3 \%$ & $84.3 \%$ & $-2.9 \%$ & $-11.7 \%$ & $12.4 \%$ & $120.4 \%$ & $-1.2 \%$ & $32.8 \%$ & $-7.1 \%$ & $-53.7 \%$ \\
\hline DMI-EH5OM1 & $-22.6 \%$ & $-61.2 \%$ & $-5.3 \%$ & $-7.9 \%$ & $7.5 \%$ & $-10.5 \%$ & $0.4 \%$ & $24.7 \%$ & $-414.4 \%$ & $-68.9 \%$ & $-6.3 \%$ & $-46.1 \%$ \\
\hline HC-HadGEM1 & $-15.3 \%$ & $-33.4 \%$ & $-15.4 \%$ & $-62.2 \%$ & $1.1 \%$ & $-24.2 \%$ & $-5.2 \%$ & $29.8 \%$ & $2.9 \%$ & $-23.7 \%$ & $2.5 \%$ & $52.9 \%$ \\
\hline IPSL-CM4 & $16.8 \%$ & $7.5 \%$ & $30.8 \%$ & $101.6 \%$ & $-9.2 \%$ & $-42.4 \%$ & $25.1 \%$ & $52.3 \%$ & $-2.3 \%$ & $-23.0 \%$ & $8.3 \%$ & $54.3 \%$ \\
\hline Ensemble-Mean & $-1.2 \%$ & $16.3 \%$ & $-2.2 \%$ & $-5.9 \%$ & $-1.9 \%$ & $-11.7 \%$ & $6.8 \%$ & $31.7 \%$ & $-6.5 \%$ & $-26.2 \%$ & $2.1 \%$ & $42.9 \%$ \\
\hline \pm inter-model STD & $\pm 13.6 \%$ & $\pm 63.0 \%$ & $\pm 14.5 \%$ & $\pm 61.4 \%$ & $\pm 13.1 \%$ & $\pm \mathbf{3 3 . 7 \%}$ & $\pm 9.2 \%$ & $\pm \mathbf{4 5 . 2 \%}$ & $\pm 8.9 \%$ & $\pm \mathbf{3 7 . 0 \%}$ & $\pm 9.1 \%$ & $\pm 114.9 \%$ \\
\hline \multicolumn{13}{|c|}{ (c) 2021-2050 without adaptation } \\
\hline & \multicolumn{2}{|c|}{ Germany } & \multicolumn{2}{|c|}{ France } & \multicolumn{2}{|c|}{ UK } & \multicolumn{2}{|c|}{ Iberia } & \multicolumn{2}{|c|}{ Poland } & \multicolumn{2}{|c|}{ Benelux } \\
\hline & MEAN & STD & MEAN & STD & MEAN & STD & MEAN & STD & MEAN & STD & MEAN & STD \\
\hline BCCR-BCM2 & $14.5 \%$ & $-10.1 \%$ & $10.8 \%$ & $10.0 \%$ & $-0.8 \%$ & $-35.7 \%$ & $11.4 \%$ & $69.9 \%$ & $-13.4 \%$ & $-68.3 \%$ & $-40.9 \%$ & $-9.9 \%$ \\
\hline CNRM-CM3 & $19.8 \%$ & $55.9 \%$ & $3.1 \%$ & $-51.8 \%$ & $8.3 \%$ & $17.8 \%$ & $1.0 \%$ & $-5.4 \%$ & $-5.9 \%$ & $-55.2 \%$ & $16.9 \%$ & $120.6 \%$ \\
\hline FUB-EGMAM & $7.1 \%$ & $14.1 \%$ & $-3.4 \%$ & $-30.7 \%$ & $19.6 \%$ & $119.5 \%$ & $-6.5 \%$ & $-17.9 \%$ & $17.4 \%$ & $157.5 \%$ & $5.3 \%$ & $26.1 \%$ \\
\hline MPI-EH5OM1 r1 & $45.5 \%$ & $103.4 \%$ & $26.5 \%$ & $3.4 \%$ & $33.7 \%$ & $77.7 \%$ & $-13.5 \%$ & $-29.6 \%$ & $17.3 \%$ & $-16.6 \%$ & $32.4 \%$ & $254.6 \%$ \\
\hline MPI-EH5OM1 r2 & $4.5 \%$ & $7.1 \%$ & $14.4 \%$ & $119.7 \%$ & $2.0 \%$ & $31.6 \%$ & $-6.9 \%$ & $0.8 \%$ & $10.1 \%$ & $13.3 \%$ & $9.7 \%$ & $30.8 \%$ \\
\hline MPI-EH5OM1 r3 & $-9.6 \%$ & $-16.3 \%$ & $2.5 \%$ & $71.9 \%$ & $1.6 \%$ & $7.5 \%$ & $-13.6 \%$ & $-37.0 \%$ & $11.1 \%$ & $22.3 \%$ & $-8.7 \%$ & $-55.8 \%$ \\
\hline DMI-EH5OM1 & $16.8 \%$ & $-13.5 \%$ & $6.6 \%$ & $-7.6 \%$ & $1.9 \%$ & $-14.8 \%$ & $3.7 \%$ & $41.9 \%$ & $53.3 \%$ & $85.3 \%$ & $1.4 \%$ & $-9.3 \%$ \\
\hline HC-HadGEM1 & $69.2 \%$ & $156.8 \%$ & $18.0 \%$ & $36.0 \%$ & $-12.7 \%$ & $-61.6 \%$ & $-11.2 \%$ & $-27.6 \%$ & $17.5 \%$ & $-23.9 \%$ & $4.8 \%$ & $80.8 \%$ \\
\hline IPSL-CM4 & $-6.1 \%$ & $-10.5 \%$ & $0.7 \%$ & $-5.0 \%$ & $3.0 \%$ & $3.8 \%$ & $-3.5 \%$ & $-16.6 \%$ & $2.2 \%$ & $-15.4 \%$ & $3.2 \%$ & $62.9 \%$ \\
\hline Ensemble-Mean & $17.9 \%$ & $31.9 \%$ & $8.8 \%$ & $16.2 \%$ & $6.3 \%$ & $16.2 \%$ & $-4.3 \%$ & $-2.4 \%$ & $12.2 \%$ & $11.0 \%$ & $7.1 \%$ & $55.6 \%$ \\
\hline \pm inter-model STD & $\pm \mathbf{2 5 . 1 \%}$ & $\pm 61.4 \%$ & $\pm 9.5 \%$ & $\pm \mathbf{5 2 . 7 \%}$ & $\pm 13.3 \%$ & $\pm \mathbf{5 5 . 5 \%}$ & $\pm \mathbf{8 . 4 \%}$ & $\pm \mathbf{3 5 . 7 \%}$ & $\pm 18.9 \%$ & $\pm 71.1 \%$ & $\pm \mathbf{1 1 . 8 \%}$ & $\pm 91.5 \%$ \\
\hline
\end{tabular}

Columbia University, available at: http://sedac.ciesin.columbia. edu/gpw, date of download: 14 August 2006, 2005.

Christensen, J. H., Christensen, O. B., Lopez, P., van Meijgaard, E., and Botzet, M.: The HIRHAM4: Regional atmospheric climate model, DMI Scientific Report 96-4, 1996.

Collins, M.: Ensembles and probabilities: a new era in the prediction of climate change, Phil. Trans. Roy. Soc. A., 365, $1957-$ 1970, 2007.

Collins, M., Booth, B. B. B., Bhaskaran, B., Harris, G. R., Murphy, J. M., Sexton, D. M. H., and Webb, M. J.: Climate model errors, feedbacks and forcings: A comparison of perturbed physics and multi-model ensembles, Clim. Dynam., 36, 1737-1766, 2011.

Della-Marta, P. M., Liniger, M. A., Appenzeller, C., Bresch, D. N., Koellner-Heck, P., and Muccione, V.: Improved estimates of the European winter wind storm climate and the risk of reinsurance loss using climate model data, J. Appl. Meteor. Climatol., 49, 2092-2120, doi:10.1175/2010JAMC2133.1, 2010.

Donat, M. G., Leckebusch, G. C., Pinto, J. G., and Ulbrich, U.:
European storminess and associated circulation weather types: future changes deduced from a multi-model ensemble of GCM simulations, Climate Res., 42, 27-43, doi:10.3354/cr00853, 2010a.

Donat, M. G., Leckebusch, G. C., Wild, S., and Ulbrich, U.: Benefits and limitations of regional multi-model ensembles for storm loss estimations, Climate Res., 44, 211-225, doi:10.3354/cr00891, 2010b.

Efron, B.: Bootstrap Methods: Another Look at the Jackknife, The Annals of Statistics, 7(1), 1-26, 1979.

Furevik, T., Bentsen, M., Drange, H., Kindem, I. K. T., Kvamsto, N. G., and Sorteberg, A.: Description and evaluation of the Bergen climate model: ARPEGE coupled with MICOM, Clim. Dynam., 21, 27-51, 2003.

Gastineau, G. and Soden, B. J.: Model projected changes of extreme wind events in response to global warming, Geophys. Res. Lett., 36, L10810, doi:10.1029/2009GL037500, 2009.

GDV: Yearbook 2006 - The German Insurance Industry, published 
Table A2. ACC signal of losses calculated in the individual RCM scenario simulations. Change signals A1B-20C without adaptation of the loss threshold for the 2 future periods in the middle (2021-2050) and at the end of 21C (2071-2100). For each region, the maximum and minimum changes of mean loss ratios (indicating the maximum spread of the ensemble) are highlighted using bold numbers.

\begin{tabular}{|c|c|c|c|c|c|c|c|c|c|c|c|c|}
\hline \multicolumn{13}{|c|}{ (a) 2071-2100 without adaptation } \\
\hline & \multicolumn{2}{|c|}{ Germany } & \multicolumn{2}{|c|}{ France } & \multicolumn{2}{|c|}{ UK } & \multicolumn{2}{|c|}{ Iberia } & \multicolumn{2}{|c|}{ Poland } & \multicolumn{2}{|c|}{ Benelux } \\
\hline & MEAN & STD & MEAN & STD & MEAN & STD & MEAN & STD & MEAN & STD & MEAN & STD \\
\hline C4I-RCA3_HCh & $-2.8 \%$ & $3.6 \%$ & $-0.4 \%$ & $-19.2 \%$ & $7.3 \%$ & $50.7 \%$ & $-6.1 \%$ & $-59.2 \%$ & $-8.6 \%$ & $-83.0 \%$ & $3.7 \%$ & $109.4 \%$ \\
\hline HC-HadRM3_HCn & $10.5 \%$ & $78.1 \%$ & $10.5 \%$ & $109.7 \%$ & $12.3 \%$ & $99.6 \%$ & $0.8 \%$ & $45.4 \%$ & $9.4 \%$ & $82.9 \%$ & $8.2 \%$ & $281.4 \%$ \\
\hline ETHZ-CLM_HCn & $19.0 \%$ & $65.6 \%$ & $9.3 \%$ & $16.7 \%$ & $27.1 \%$ & $202.3 \%$ & $0.6 \%$ & $32.3 \%$ & $8.0 \%$ & $101.5 \%$ & $10.8 \%$ & $93.6 \%$ \\
\hline DMI-HIRHAM_C & $2.5 \%$ & $-22.2 \%$ & $-2.1 \%$ & $-21.5 \%$ & $15.8 \%$ & $84.9 \%$ & $-7.8 \%$ & $-25.7 \%$ & $10.4 \%$ & $67.2 \%$ & $-1.7 \%$ & $-23.4 \%$ \\
\hline SMHI-RCA3_B & $17.6 \%$ & $-6.2 \%$ & $15.9 \%$ & $99.1 \%$ & $23.0 \%$ & $57.3 \%$ & $7.9 \%$ & $125.7 \%$ & $-1.7 \%$ & $-24.0 \%$ & $4.4 \%$ & $10.6 \%$ \\
\hline MPI-REMO_E5_3 & $5.3 \%$ & $55.7 \%$ & $0.0 \%$ & $67.8 \%$ & $0.9 \%$ & $-24.1 \%$ & $-3.5 \%$ & $-34.4 \%$ & $2.8 \%$ & $13.2 \%$ & $1.8 \%$ & $81.2 \%$ \\
\hline DMI-HIRHAM_E5_3 & $15.2 \%$ & $34.1 \%$ & $12.1 \%$ & $39.0 \%$ & $12.7 \%$ & $-31.8 \%$ & $-43.5 \%$ & $-14.5 \%$ & $19.6 \%$ & $351.7 \%$ & $9.1 \%$ & $72.3 \%$ \\
\hline KNMI-RACMO2_E5_1 & $\mathbf{5 4 . 8 \%}$ & $114.0 \%$ & $8.7 \%$ & $6.2 \%$ & $63.6 \%$ & $288.0 \%$ & $-11.8 \%$ & $8.3 \%$ & $20.4 \%$ & $20.0 \%$ & $39.6 \%$ & $252.2 \%$ \\
\hline KNMI-RACMO2_E5_2 & $14.3 \%$ & $26.7 \%$ & $14.8 \%$ & $37.8 \%$ & $35.4 \%$ & $10.2 \%$ & $-5.1 \%$ & $60.0 \%$ & $-3.7 \%$ & $-40.3 \%$ & $9.9 \%$ & $10.2 \%$ \\
\hline KNMI-RACMO2_E5_3 & $33.6 \%$ & $274.6 \%$ & $-1.7 \%$ & $-13.4 \%$ & $8.5 \%$ & $36.7 \%$ & $-7.9 \%$ & $-0.9 \%$ & $14.1 \%$ & $128.7 \%$ & $4.3 \%$ & $35.1 \%$ \\
\hline SMHI-RCA3_E5_3 & $-4.5 \%$ & $-9.9 \%$ & $-3.9 \%$ & $-38.4 \%$ & $-2.6 \%$ & $-17.3 \%$ & $-9.8 \%$ & $-30.5 \%$ & $-4.3 \%$ & $-11.2 \%$ & $-2.6 \%$ & $-14.2 \%$ \\
\hline Ensemble-Mean & $15.1 \%$ & $\mathbf{5 5 . 8 \%}$ & $5.7 \%$ & $25.8 \%$ & $18.5 \%$ & $68.8 \%$ & $-4.2 \%$ & $9.7 \%$ & $6.1 \%$ & $\mathbf{5 5 . 2 \%}$ & $8.0 \%$ & $82.6 \%$ \\
\hline \pm inter-model STD & $\pm \mathbf{1 7 . 1 \%}$ & $\pm 83.8 \%$ & $\pm \mathbf{7 . 4 \%}$ & $\pm \mathbf{4 9 . 9 \%}$ & $\pm 18.6 \%$ & $\pm 99.1 \%$ & $\pm \mathbf{5 . 6 \%}$ & $\pm \mathbf{5 3 . 0} \%$ & $\pm \mathbf{9 . 9 \%}$ & $\pm 117.6 \%$ & $\pm 11.4 \%$ & $\pm \mathbf{1 0 1 . 2 \%}$ \\
\hline \multicolumn{13}{|c|}{ (b) 2021-2050 without adaptation } \\
\hline & \multicolumn{2}{|c|}{ Germany } & \multicolumn{2}{|c|}{ France } & \multicolumn{2}{|c|}{ UK } & \multicolumn{2}{|c|}{ Iberia } & \multicolumn{2}{|c|}{ Poland } & \multicolumn{2}{|c|}{ Benelux } \\
\hline & MEAN & STD & MEAN & STD & MEAN & STD & MEAN & STD & MEAN & STD & MEAN & STD \\
\hline C4I-RCA3_HCh & $-1.7 \%$ & $-32.1 \%$ & $-1.8 \%$ & $-30.6 \%$ & $8.4 \%$ & $41.4 \%$ & $4.3 \%$ & $-31.4 \%$ & $-5.8 \%$ & $-70.4 \%$ & $1.9 \%$ & $22.6 \%$ \\
\hline HC-HadRM3_HCn & $6.6 \%$ & $26.5 \%$ & $0.0 \%$ & $-4.4 \%$ & $9.0 \%$ & $81.8 \%$ & $-3.5 \%$ & $-29.6 \%$ & $6.7 \%$ & $87.0 \%$ & $5.7 \%$ & $92.4 \%$ \\
\hline METNO-HIRHAM_HCn & $-11.7 \%$ & $-57.9 \%$ & $-10.4 \%$ & $-39.5 \%$ & $9.2 \%$ & $79.9 \%$ & $-7.6 \%$ & $-15.1 \%$ & $-4.5 \%$ & $-47.8 \%$ & $0.3 \%$ & $31.2 \%$ \\
\hline ETHZ-CLM_HCn & $0.0 \%$ & $-14.0 \%$ & $1.4 \%$ & $-7.1 \%$ & $21.1 \%$ & $122.0 \%$ & $-4.5 \%$ & $-23.9 \%$ & $2.1 \%$ & $7.1 \%$ & $1.8 \%$ & $6.4 \%$ \\
\hline CNRM-RM4.5_C & $1.9 \%$ & $42.3 \%$ & $0.4 \%$ & $27.0 \%$ & $1.8 \%$ & $11.5 \%$ & $1.1 \%$ & $35.7 \%$ & $2.2 \%$ & $96.7 \%$ & $0.4 \%$ & $50.6 \%$ \\
\hline DMI-HIRHAM_C & $3.9 \%$ & $-32.5 \%$ & $0.8 \%$ & $-3.1 \%$ & $25.3 \%$ & $49.3 \%$ & $-2.0 \%$ & $-13.1 \%$ & $-0.9 \%$ & $-16.7 \%$ & $-0.9 \%$ & $-10.4 \%$ \\
\hline METNO-HIRHAM_B & $-4.4 \%$ & $-47.4 \%$ & $-3.0 \%$ & $-14.2 \%$ & $15.5 \%$ & $-3.6 \%$ & $6.0 \%$ & $24.5 \%$ & $3.1 \%$ & $44.8 \%$ & $-3.8 \%$ & $-62.7 \%$ \\
\hline SMHI-RCA3_B & $19.9 \%$ & $29.7 \%$ & $16.8 \%$ & $201.5 \%$ & $25.1 \%$ & $83.6 \%$ & $12.7 \%$ & $240.9 \%$ & $-5.7 \%$ & $-48.0 \%$ & $5.0 \%$ & $-15.7 \%$ \\
\hline MPI-REMO_E5_3 & $0.1 \%$ & $12.1 \%$ & $-3.3 \%$ & $4.4 \%$ & $0.6 \%$ & $-1.9 \%$ & $-1.7 \%$ & $-11.5 \%$ & $5.5 \%$ & $83.3 \%$ & $-2.8 \%$ & $-53.7 \%$ \\
\hline DMI-HIRHAM_E5_3 & $11.9 \%$ & $34.3 \%$ & $-0.8 \%$ & $-7.9 \%$ & $2.6 \%$ & $-37.3 \%$ & $-3.7 \%$ & $-13.2 \%$ & $1.9 \%$ & $39.3 \%$ & $2.8 \%$ & $74.8 \%$ \\
\hline KNMI-RACMO2_E5_1 & $32.1 \%$ & $5.0 \%$ & $9.4 \%$ & $-1.7 \%$ & $45.5 \%$ & $154.3 \%$ & $-18.0 \%$ & $-45.1 \%$ & $24.1 \%$ & $89.0 \%$ & $40.7 \%$ & $167.3 \%$ \\
\hline KNMI-RACMO2_E5_2 & $2.3 \%$ & $-8.1 \%$ & $28.2 \%$ & $151.0 \%$ & $21.9 \%$ & $7.4 \%$ & $0.5 \%$ & $22.4 \%$ & $-8.3 \%$ & $-46.9 \%$ & $15.4 \%$ & $45.5 \%$ \\
\hline KNMI-RACMO2_E5_3 & $11.4 \%$ & $150.3 \%$ & $-0.9 \%$ & $23.6 \%$ & $-0.5 \%$ & $1.3 \%$ & $-8.1 \%$ & $-27.6 \%$ & $6.6 \%$ & $56.1 \%$ & $-4.9 \%$ & $-13.0 \%$ \\
\hline SMHI-RCA3_E5_3 & $-5.5 \%$ & $-11.0 \%$ & $-4.4 \%$ & $-14.2 \%$ & $-10.4 \%$ & $-29.0 \%$ & $-8.5 \%$ & $-28.1 \%$ & $0.4 \%$ & $-8.0 \%$ & $-8.9 \%$ & $-43.4 \%$ \\
\hline Ensemble-Mean & $4.8 \%$ & $6.9 \%$ & $2.3 \%$ & $20.3 \%$ & $12.5 \%$ & $40.0 \%$ & $-2.3 \%$ & $6.1 \%$ & $2.0 \%$ & $19.0 \%$ & $3.8 \%$ & $20.8 \%$ \\
\hline \pm inter-model STD & $\pm 11.2 \%$ & $\pm \mathbf{5 1 . 7 \%}$ & $\pm \mathbf{9 . 8 \%}$ & $\pm 69.0 \%$ & $\pm 14.3 \%$ & $\pm \mathbf{5 7 . 4 \%}$ & $\pm 7.4 \%$ & $\pm 71.6 \%$ & $\pm \mathbf{8 . 0 \%}$ & $\pm \mathbf{5 9 . 2 \%}$ & $\pm 12.1 \%$ & $\pm 62.9 \%$ \\
\hline
\end{tabular}

by: Gesamtverband der Deutschen Versicherungswirtschaft e.V. (German Insurance Association), www.gdv.de, 2006.

GDV: Yearbook 2009 - The German Insurance Industry, published by: Gesamtverband der Deutschen Versicherungswirtschaft e.V. (German Insurance Association), www.gdv.de, 2009.

Gibelin, A. L. and Déqué, M.: Anthropogenic climate change over the Mediterranean region simulated by a global variable resolution model, Clim. Dyn., 20, 327-339, 2003.

Giorgi, F.: Regional climate modeling: Status and perspectives, J. Phys. IV France, 139, 101-118, doi:10.1051/jp4:2006139008, 2006.

Goyette, S., Brasseur, O., and Beniston, M.: Application of a new wind gust parameterisation: Multiple scale studies performed with the Canadian regional climate model, J. Geophys. Res., 108(D13), 4374, doi:10.1029/2002JD002646, 2003.

Hagedorn, R., Doblas-Reyes, F. J., and Palmer, T. N.: The rationale behind the success of multi-model ensembles in seasonal forecasting - I. Basic concept, Tellus, 57, 219-233, doi:10.1111/j.1600-0870.2005.00103.x, 2005.

Hofherr, T. and Kunz, M.: Extreme wind climatology of winter storms in Germany, Clim. Res., 41, 105-123, 2010.

Huebener, H., Cubasch, U., Langematz, U., Spangehl, T., Niehörster, F., Fast, I., and Kunze, M.: Ensemble climate simulations using a fully coupled ocean-troposphere-stratosphere GCM, Phil. Trans. Royal Soc. A, 365, 2089-2101, 2007.
Jacob, D.: A note to the simulation of the annual and inter-annual variability of the water budget over the Baltic Sea drainage basin, Meteorol. Atmos. Phys., 77, 61-73, 2001.

Jacob, D. and Podzun, R.: Sensitivity studies with the regional model REMO, Meteorol. Atmos. Phys., 63, 119-129, 1997.

Jaeger, E. B., Anders, I., Lüthi, D., Rockel, B., Schär, C., and Seneviratne, S. I.: Analysis of ERA40-driven CLM simulations for Europe, Meteorol Z., 17, 349-367, 2008.

Johns, T. C., Durman, C. F., Banks, H. T., Roberts, M. J., McLaren, A. J., Ridley, J. K., Senior, C. A., Williams, K. D., Jones, A., Rickard, G. J., Cusack, S., Ingram, W. J., Crucifix, M., Sexton, D. M. H., Joshi, M. M., Dong, B. W., Spencer, H., Hill, R. S. R., Gregory, J. M., Keen, A. B., Pardaens, A. K., Lowe, J. A., BodasSalcedo, A., Stark, S., and Searl, Y.: The new Hadley Centre Climate Model (HadGEM1): Evaluation of coupled simulations, J. Climate, 19, 1327-1353, 2006.

Jones, R. G., Murphy, J. M., and Noguer, M.: Simulation of climatechange over Europe using a nested regional-climate model. Part I: Assessment of control climate, including sensitivity to location of lateral boundaries, Q. J. Roy. Meteor. Soc., 121, 1413-1449, 1995.

Jungclaus, J. H., Keenlyside, H., Botzet, M., Haak, H., Luo, J.-J., Latif, M., Marotzke, J., Mikolajewitcz, U., and Roeckner, E.: Ocean Circulation and tropical variability in the coupled model ECHAM5/MPI-OM, J. Climate, 19, 3952-3972, 2006. 
Kjellström, E., Bärring, L., Gollvik, S., Hansson, U., Jones, C., Samuelsson, P., Rummukainen, M., Ullerstig, A., Willén, U., and Wyser, K.: A 140-year simulation of European climate with the new version of the Rossby Centre regional atmospheric climate model (RCA3), Reports Meteorology and Climatology, 108, SMHI, SE-60176 Norrköping, Sweden, 54 pp., 2005.

Klawa, M. and Ulbrich, U.: A model for the estimation of storm losses and the identification of severe winter storms in Germany, Nat. Hazards Earth Syst. Sci., 3, 725-732, doi:10.5194/nhess-3725-2003, 2003.

Knippertz, P., Ulbrich, U., and Speth, P.: Changing cyclones and surface wind speeds over the North Atlantic and Europe in a transient GHG experiment, Climate Res., 15, 109-122, 2000.

Kunz, M., Mohr, S., Rauthe, M., Lux, R., and Kottmeier, Ch.: Assessment of extreme wind speeds from Regional Climate Models - Part 1: Estimation of return values and their evaluation, Nat. Hazards Earth Syst. Sci., 10, 907-922, doi:10.5194/nhess10-907-2010, 2010.

Lambert, S. J. and Fyfe, J. C.: Changes in winter cyclone frequencies and strengths simulated in enhanced greenhouse warming experiments: results from the models participating in the IPCC diagnostic exercise, Clim. Dynam., 26, 713-728, 2006.

Leckebusch, G. C. and Ulbrich, U.: On the relationship between cyclones and extreme windstorm events over Europe under climate change, Global Planet Change, 44, 181-193, doi:10.1016/j.gloplacha.2004.06.011, 2004.

Leckebusch, G. C., Koffi, B., Ulbrich, U., Pinto, J. G., Spangehl, T., and Zacharias, S.: Analysis of frequency and intensity of winter storm events in Europe on synoptic and regional scales from a multi-model perspective, Climate Res., 31, 59-74, 2006.

Leckebusch, G. C., Ulbrich, U., Fröhlich, L., and Pinto, J. G.: Property loss potentials for European midlatitude storms in a changing climate, Geophys. Res. Lett., 34, L05703, doi:10.1029/2006GL027663, 2007.

Leckebusch, G. C., Renggli, D., and Ulbrich, U.: Development and Application of an Objective Storm Severity Measure for the Northeast Atlantic Region, Meteorol. Z., 17, 575-587, 2008a.

Leckebusch, G. C., Donat, M. G., Ulbrich, U., and Pinto, J. G.: Mid-latitude Cyclones and Storms in an Ensemble of European AOGCMs under ACC, CLIVAR Exchanges, 13, 3, 3-5, ISSN 1026-0471, http://eprints.soton.ac.uk/55670/01/Exch_46_final3. pdf, 2008b.

Legutke, S. and Voss, R.: The Hamburg Atmosphere-Ocean Coupled Circulation Model ECHO-G, Technical report, 18, 62 pp., German Climate Computer Centre (DKRZ), 1999.

Lenderink, G., van den Hurk, B., van Meijgaard, E., van Ulden, A., and Cujipers, H.: Simulation of present-day climate in RACMO2: rst results and model developments, KNMI Technical Report, 252, 24, 2003.

Manzini, E. and McFarlane, N. A.: The effect of varying the source spectrum of a gravity wave parameterization in a middle atmosphere general circulation model, J. Geophys. Res., 103, 3152331539, 1998.

Marti, O., Braconnot, P., Bellier, J., Benshila, R., Bony, S., Brockmann, P., Cadule, P., Caubel, A., Denvil, S., Dufresne, J. L., Fairhead, L., Filiberti, M. A., Foujols, M.-A., Fichefet, T., Friedlingstein, P., Goosse, H., Grandpeix, J. Y., Hourdin, F., Krinner, G., Lévy, C., Madec, G., Musat, I., deNoblet, N., Polcher, J., and Talandier, C.: The new IPSL climate system model: IPSL-CM4,
Note du Pôle de Modélisation, 26, ISSN 1288-1619, 2005.

Martin, G. M., Ringer, M. A., Pope, V. D., Jones, A., Dearden, C., and Hinton, T. J.: The Physical Properties of the Atmosphere in the New Hadley Centre Global Environmental Model (HadGEM1). Part I: Model Description and Global Climatology, J. Climate, 19, 1274-1301, 2006.

Munich, Re.: Naturkatastrophen in Deutschland: Schadenerfahrungen und Schadenpotentiale, Publication of the Munich Re, Order Number 2798-E-d www.munichre.com, 1999.

Munich, Re.: Zwischen Hoch und Tief - Wetterrisiken in Mitteleuropa, Eidition Wissen, Publication of the Munich Re, Order Number 302-05481, www.munichre.com, 2007.

Murphy, J. M., Sexton, D. M., Barnett, D. N., Jones, G. S., Webb, M. J., Collins, M., and Stainforth, D. A.: Quantification of modelling uncertainties in a large ensemble of climate change simulations, Nature, 430(7001), 768-772, 2004.

Palmer, T. N. and Räisänen, J.: Quantifying the risk of extreme seasonal precipitation events in a changing climate, Nature, 415 , 512-514 2002.

Pinto, J. G., Fröhlich, E. L., Leckebusch, G. C., and Ulbrich, U.: Changing European storm loss potentials under modified climate conditions according to ensemble simulations of the ECHAM5/MPI-OM1 GCM, Nat. Hazards Earth Syst. Sci., 7, 165-175, doi:10.5194/nhess-7-165-2007, 2007.

Räisänen, J.: How reliable are climate models?, Tellus 59A, 2-29, 2007.

Ringer, M. A., Martin, G. M., Greeves, C. Z., Hinton, T. J., James, P. M., Pope, V. D., Scaife, A. A., Stratton, R. A., Inness, P. M., Slingo, J. M., and Yang, G.-Y.: The Physical Properties of the Atmosphere in the New Hadley Centre Global Environmental Model (HadGEM1). Part II: Aspects of Variability and Regional Climate, J. Climate, 19, 1302-1326, 2006.

Rockel, B. and Woth, K.: Extremes of near-surface wind speed over Europe and their future changes as estimated from an ensemble of RCM simulations, Climatic Change, 81, 267-280, 2007.

Salas-Mélia, D., Chauvin, F., Déqué, M., Douville, H., Gueremy, J. F., Marquet, P., Planton, S., Royer, J. F., and Tyteca, S.: Description and validation of the CNRM-CM3 global coupled model, CNRM working note 103, 2005.

Samuelsson, P., Jones, C., Willén, U., Ullerstig, A., Gollvik, S., Hansson, U., Kjellström, E., Nikulin, G., and Wyser, K.: The Rossby Centre Regional Climate Model RCA3: Model description and performance, Tellus A, 63, 4-23, doi:10.1111/j.16000870.2010.00478.x, 2011.

Schrodin, R.: Dokumentation des EM/DM Systems, DWD, available at: Deutscher Wetterdienst, Postfach 100465, 63004 Offenbach am Main, 1995.

Stainforth, D. A., Aina, T., Christensen, C., Collins, M., Faull, N., Frame, D. J., Kettleborough, J. A., Knight, S., Martin, A., Murphy, J. M., Piani, C., Sexton, D., Smith, L. A., Spicer, R. A., Thorpe, A. J., and Allen, M. R.: Uncertainty in predictions of the climate response to rising levels of greenhouse gases, Nature, 433(7024), 403-406, 2005.

Steppeler, J., Dom, G., Schättler, U., Bitzer, H. W., Grassmann, A., Damrath, U., and Gregoric, G.: Mesogamma scale forecasts using the nonhydrostatic model LM, Meteor. Atmos. Phys., 82, 75-96, 2003.

Ulbrich, U., Pinto, J. G., Kupfer, H., Leckebusch, G. C., Spangehl, T., and Reyers, M.: Northern Hemisphere Storm Tracks in an en- 
semble of IPCC climate change simulations, J. Clim., 21, 16691679, 2008.

Uppala, S. M., Allberg, K., Simmons, P. W., Andrae, A. J., Da Costa, U., Bechtold, V., Fiorino, M., Gibson, J. K., Haseler, J., Hernandez, A., Kelly, G. A., Li, X., Onogi, K., Saarinen, S., Sokka, N., Allan, R. P., Andersson, E., Arpe, K., Balmaseda, M. A., Beljaars, A. C. M., Van De Berg, L., Bidlot, J., Bormann, N., Caires, S., Chevallier, F., Dethof, A., Dragosavac, M., Fisher, M., Fuentes, M., Hagemann, S., Holm, E., Hoskins, B. J., Isaksen, L., Janssen, P. A., Jenne, R., Mcnally, A. P., Mahfouf, J.-F., Morcrette, J.-J., Rayner, N. A., Saunders, R., Simon, P., Sterl, A., Trenberth, K. E., Untch, A., Vasiljevic, D., Viterbo, P., and Woollen, J.: The ERA-40 re-analysis, Q. J. Roy. Meteorol. Soc., 131, 2961-3012, 2005. van der Linden, P. and Mitchell, J. F. B.: ENSEMBLES: Climate Change and its Impacts: Summary of research and results from the ENSEMBLES project, Met Office Hadley Centre, Exeter, UK, 160 pp., 2009.

Wang, X. L., Zwiers, F. W., Swail, V. R., and Feng, Y.: Trends and Variability of Storminess in the Northeast Atlantic Region, 1874-2007, Clim. Dyn., 33, 1179-1195, doi:10.1007/s00382008-0504-5, 2009.

White, P. W.: IFS Documentation CY23r4. Part IV: Physical Processes (CY23r4), http://www.ecmwf.int/research/ifsdocs/ CY23r4/, 2003.

Žagar, N., Žagar, M., Cedilnik, J., Gregoriè, G., and Rakovec, J.: Validation of mesoscale low-level winds obtained by dynamical downscaling of ERA40 over complex terrain, Tellus A, 58, 445455, doi:10.1111/j.1600-0870.2006.00186.x, 2006. 